\title{
Article \\ Nonlinear Hydrodynamic Analysis of Ships Moored in a VLFS Service Basin in the East Mediterranean Sea
}

\author{
Roy Gafter ${ }^{1,2, *(D)}$ and Nitai Drimer ${ }^{1}$ (D) \\ 1 Faculty of Mechanical Engineering, Technion-Israel Institute of Technology, \\ Haifa 32000, Israel; nitaid@technion.ac.il \\ 2 CAMERI-Coastal and Marine Engineering Research Institute, Haifa 32000, Israel \\ * Correspondence: roygafter@gmail.com; Tel.: +972-54-5227211
}

Citation: Gafter, R.; Drimer, N. Nonlinear Hydrodynamic Analysis of Ships Moored in a VLFS Service Basin in the East Mediterranean Sea. J. Mar. Sci. Eng. 2022, 10, 382. https://doi.org/10.3390/ jmse10030382

Academic Editor: José A. F. O. Correia

Received: 7 February 2022

Accepted: 3 March 2022

Published: 7 March 2022

Publisher's Note: MDPI stays neutral with regard to jurisdictional claims in published maps and institutional affiliations.

Copyright: (C) 2022 by the authors. Licensee MDPI, Basel, Switzerland. This article is an open access article distributed under the terms and conditions of the Creative Commons Attribution (CC BY) license (https:// creativecommons.org/licenses/by/ $4.0 /)$.

\begin{abstract}
Very large floating structure (VLFS) is an environmentally sensitive technology which creates artificial land at sea. Designated for the open sea, the Delta is a new type of VLFS. Formed, inherently, by the innovative geometry, the sheltered basin is a unique feature of the Delta. Its year-round operability as the gateway of the structure directly affects the Delta's utilization. This study examines the basin in terms of its operability as a service port. Relying on potential flow theory and applying the boundary element method, we conducted a nonlinear hydrodynamic analysis of a moored vessel at the basin. It consists of a time-domain simulation of a tanker, berthed via nonlinear mooring system along the Delta's side hull under severe wave conditions typical to the East Mediterranean Sea. The system is evaluated in terms of acceptable motion of the ship and permissible load on the mooring system. The favorable results indicate that the basin enables most cargo handling operations under waves conditions of $\mathrm{H}_{\mathrm{mo}}=2.5 \mathrm{~m}$, and minimal downtime of less than $6 \%$ of the year. In this paper we present the analysis procedure, the evaluation criteria, and the mooring system's design. The study results and their significance are presented and discussed as well.
\end{abstract}

Keywords: VLFS; hydrodynamic analysis; mooring design; time domain

\section{Introduction}

Overexploitation of the land, enhanced by the constant rise of population density in coastal regions is a major global concern [1-3]. A very large floating structure (VLFS) is an environmentally sensitive alternative for the creation of artificial land at sea [4-7]. Offering broad space and high stability, it can be utilized for the accommodation of landbased operations out at sea. Thus, it may provide a much-needed relief and enable a more sustainable development in coastal regions.

VLFS types are traditionally categorized by their hull configurations into the pontoon or the semisubmersible types $[8,9]$. The Delta-type VLFS $[10,11]$ is a newly developed concept. It is designed to operate at intermediate open sea condition and to withstand severe weather conditions with minimal downtime. The unique delta shape (see Figures 1 and 3) is designated to provide high hydrodynamic efficiency and a broad operational area. The innovative hull design maintains acceptable loads and motions and minimizes the structural complexity. A unique and important feature of the Delta concept is the integrated sheltered basin. Protected from the incoming waves by the frontal delta and the side hulls, the sheltered basin provides a year-round access to and from the facility. The basin's ability to host a wide range of cargo handling operations with minimal downtime directly influences the operability and the utilization range of the Delta. Drimer and Gafter [10] introduced the Delta VLFS, elaborated on the design considerations, studied the hydrodynamic attributes, and showed the favorable performance of the structure. Focusing on the structural design aspects of the Delta, [11] presented a primary strength assessment tool, developed for the Delta. This study focuses on the sheltered basin and examines 
its operability as a service port and, as an expansion to the mentioned hydrodynamic study, we constructed an analysis procedure so it may be utilized as a design evaluation tool. The study aims to assess by practical engineering methods the performance of the sheltered basin serving the VLFS. While the same practice is common to the development of harbors, by means of numerical or physical agitation models, we here applied it to assess an innovative concept of VLFS, to extend the use of the open sea.

For the mooring design [10], as well as for the structural design of the VLFS [11], we applied extreme storms. However, for the operability aspects, as the downtime is in the order of few percent, we indicated the limit storms that will disturb the operability, which are storms that statistically appear every year. This is a common practice for harbors design, where the stability of the breakwaters is tested for extreme storms (stability models), while the operability is tested for storms that statistically appear every year (agitation models) [12]. We followed this practice for the VLFS. For the storms that statistically dominate the downtime, the representation of a real sea by a spectrum of nonbreaking waves is practical and valid.

The hydrodynamic performances of the Delta are fundamental to the operability and feasibility of the concept. While the motion attributes of the hull were fairly examined in previous work, as presented by [10], under severe wave conditions, the motion response of the structure was extremely low. The results of the application of the comfort evaluation criteria, presented in [10], clearly demonstrated that low motion response. In addition, the time-domain analysis of the moored structure, presented in [10], showed that under severe oblique waves, the structure maintained its preferable position, oscillating within acute angle while facing nearly head-on to the incoming waves. Presented in [10] as well, the operability of the sheltered basin was studied in terms of wave agitation parameters alone. This work expands the operability research of the sheltered basin by conducting a hydrodynamic study of a typical ship moored to the Delta under severe sea conditions. As a significant part of the methodology, developed for the advancement of the Delta concept, the preliminary design of the mooring system aims to provide an initial frame of reference for basic evaluation and qualitative measure. The behavior of the system (the interacting Delta VLFS and moored ship) was simulated in the time domain, enabling the modeling of the mooring system with realistic nonlinear response characteristics. Such a simulation fairly represents the actual motion of the berthed ship and allow the evaluation of the sheltered basin in terms of its operability as the service port of the Delta. While, at this stage, we implemented the mooring analysis for the evaluation of the design that was hydrodynamically optimized in early stages, on later design stages (as more specific requirements emerge), the procedure may be readily used for other geometrical configurations as well.

Following the introduction, Section 2 presents the theoretical background, the analysis methods, the analysis tools, and provides the system's description, evaluation criteria, and the load cases. Section 3 details the results and, finally, Section 4 presents a discussion and conclusions.

\section{Materials and Methods}

\subsection{Analysis Method}

The motion response to waves is fundamental to most design stages of a VLFS and is at the base of many of the operability and maintenance considerations [13-15]. In this study, the analyzed hulls have substantial dimensions, and the hydrodynamics is characterized by a large Reynolds number (ratio of inertia to viscous forces). Therefore, we may neglect the viscous forces and use potential flow theory for the resolution of the wave-(large) body interaction problem [16]. Several methods may be implemented for the study of dynamic fluid structure interaction systems: the finite volume method [17], finite-element-based arbitrary Lagrangian-Eulerian method [18], smoothed particle hydrodynamics [19], and hybrid methods $[20,21]$. However, the BEM practical technique is implemented extensively for the research and design of VLFS [22]. To analyze hulls, such as that of the Delta, at 
zero forward speed, it is common to use the boundary element method (BEM). Relying on potential flow theory, the BEM is used for the numeric resolution of the linearized wavestructure interaction problem. The calculation of the first-order motions of large floating bodies under regular waves are almost exclusively obtained using the BEM [23,24]. In such procedures, second-order loads and motions, or viscosity effects, may be approximated by postprocessing the linear solution [25]. The real sea emulation is conducted by combining the first-order response with a spectral representation of real conditions [24,26-29]. While it is obvious that the motion response of a floating structure under wave conditions is governed by the dynamic wave-structure interaction, it is important to note that it may govern the structural response as well. Specifically, in the field of VLFS, the hydroelastic response of flexible structures such as the pontoon of a VLFS is a major concern as it governs both the motion and the structural response of the structure [30]. As presented by [31-33], for example, the dynamic coupling effect of the interaction between the structural response and the wave loading may have a significant amplification/deamplification effect on the system. However, as presented in [10], we conducted our research under the assumption that in the case of the Delta, such effects are relatively low and may be neglected.

As presented by [34-36], the ANSYS AQWA (BEM) (Ansys Inc., Canonsburg, PA, USA) software tool provides a high accuracy and valid description of the motion characteristics of floating structures. Therefore, the study consisted in employing AQWA for the hydrodynamic analysis and time-domain simulation of the system. AQWA-LINE (Ansys Inc., Canonsburg, PA, USA) solves wave-structure interaction linear problems to obtain the hydrodynamic database at a representative range of wave periods. AQWA-LIBRIUM (Ansys Inc., Canonsburg, PA, USA) evaluates the equilibrium state of the system applied to the steady forces, and, finally, AQWA-DRIFT (Ansys Inc., Canonsburg, PA, USA) simulates the time-domain response. The simulation emulates real sea conditions, accounts (approximately) for the second-order slow-varying wave loads and enables the modeling of a nonlinear mooring system in the time domain. The formulation of the wave-structure interaction problem as well as the mathematical description of the numeric solution and its postprocessing for the time-domain simulation are detailed in [37].

\subsection{Conceptual Framework}

\subsubsection{Model Description}

As presented in Figures 1 and 2, the system consists of the Delta VLFS, anchored to the seabed via a single point mooring (SPM) system, and a tanker, berthed along the side hull in the sheltered basin. As presented by [10], the SPM system assures that the Delta's position is maintained close to the optimal head-on direction to the waves, with small variations. Therefore, to reduce the transition response, we specified the incoming wave initial direction to the head-on to bow direction. As a result, the calculation of the equilibrium position by AQWA-LIBRIUM was significantly shortened.

The layout of the mooring system (see Figure 2) of the tanker to the Delta berth, followed the Oil Companies International Marine Forum (OCIMF) recommendations [38]. At the initial position, the vertical angles of all lines were less than $5^{\circ}$ and so were the horizontal angles of the spring lines. The breast lines were, initially, perpendicular to the berth and the ship and all the lines were approximately $40 \mathrm{~m}$ long (upstretched). The fenders were spread evenly along the berth, $28.7 \mathrm{~m}$ apart.

Figure 3 and Table 1 present the geometry and main dimensions of the Delta VLFS as modeled for the mooring analysis. This geometry results from a previous design and analysis of the hydrodynamic and structural aspects $[10,11]$. 


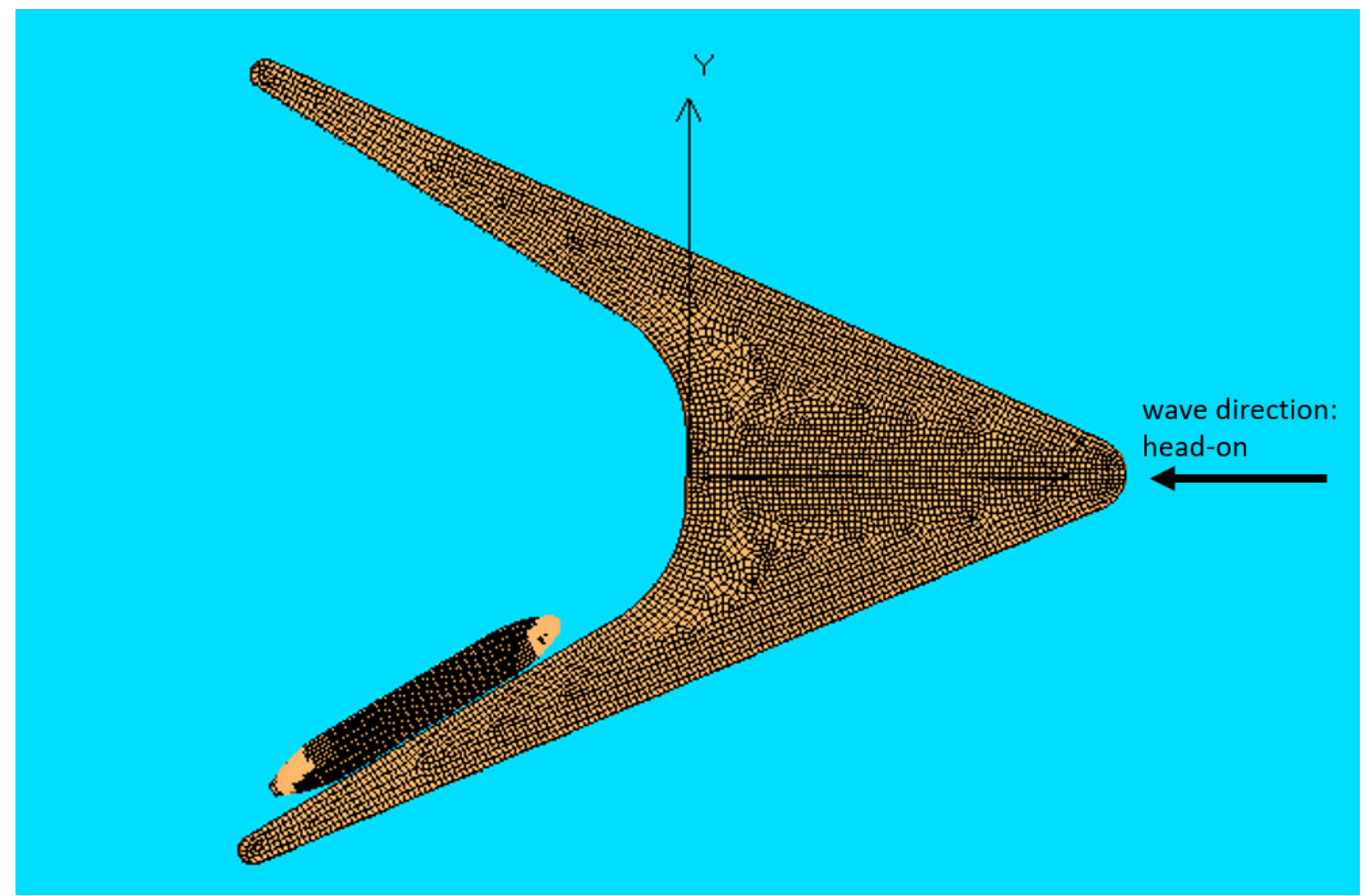

Figure 1. Layout of the moored ship at the sheltered basin of the Delta VLFS.
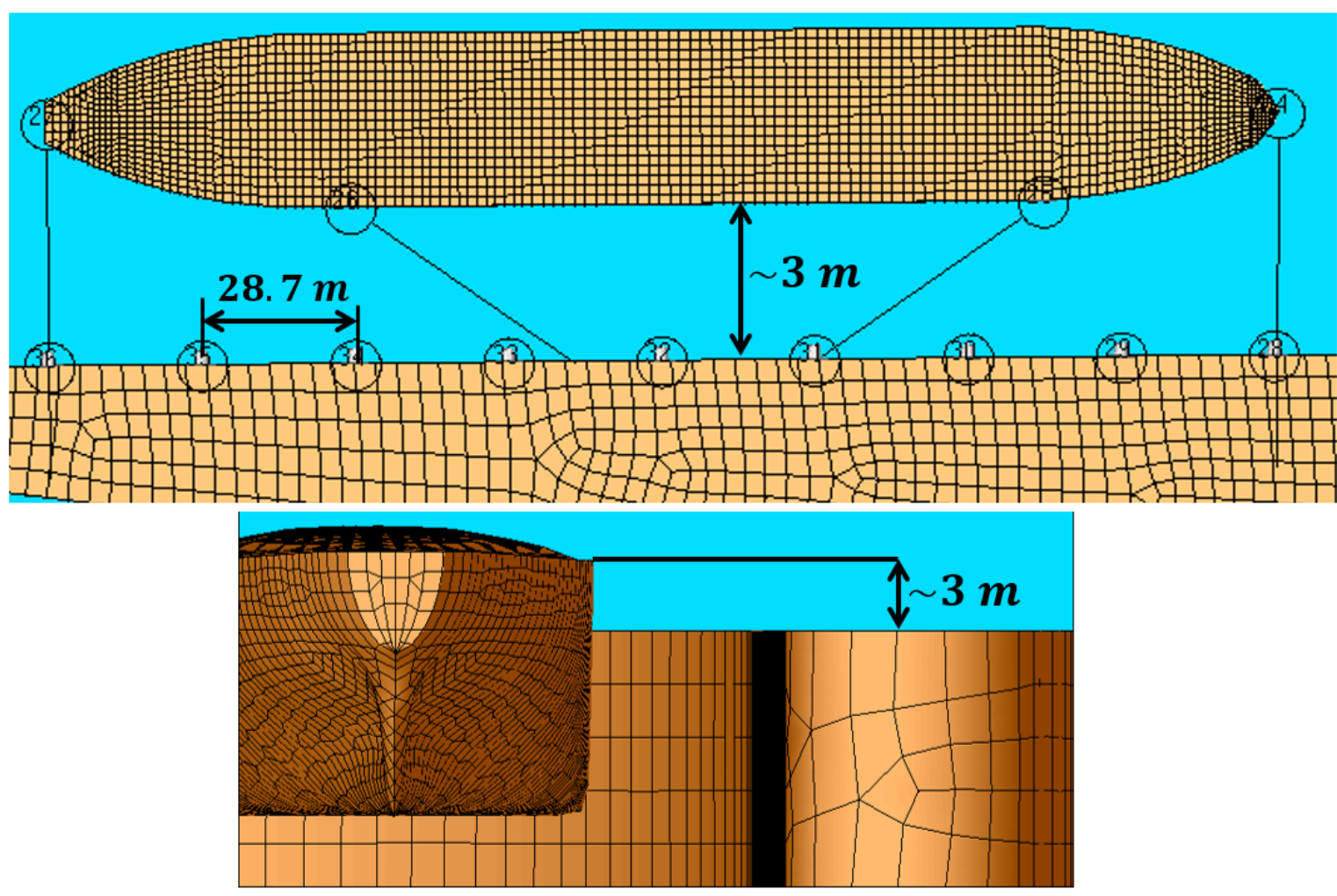

Figure 2. The berth mooring system layout. Top: view from above; bottom: view from the back. Note: the figures are slightly distorted for visual purposes. 


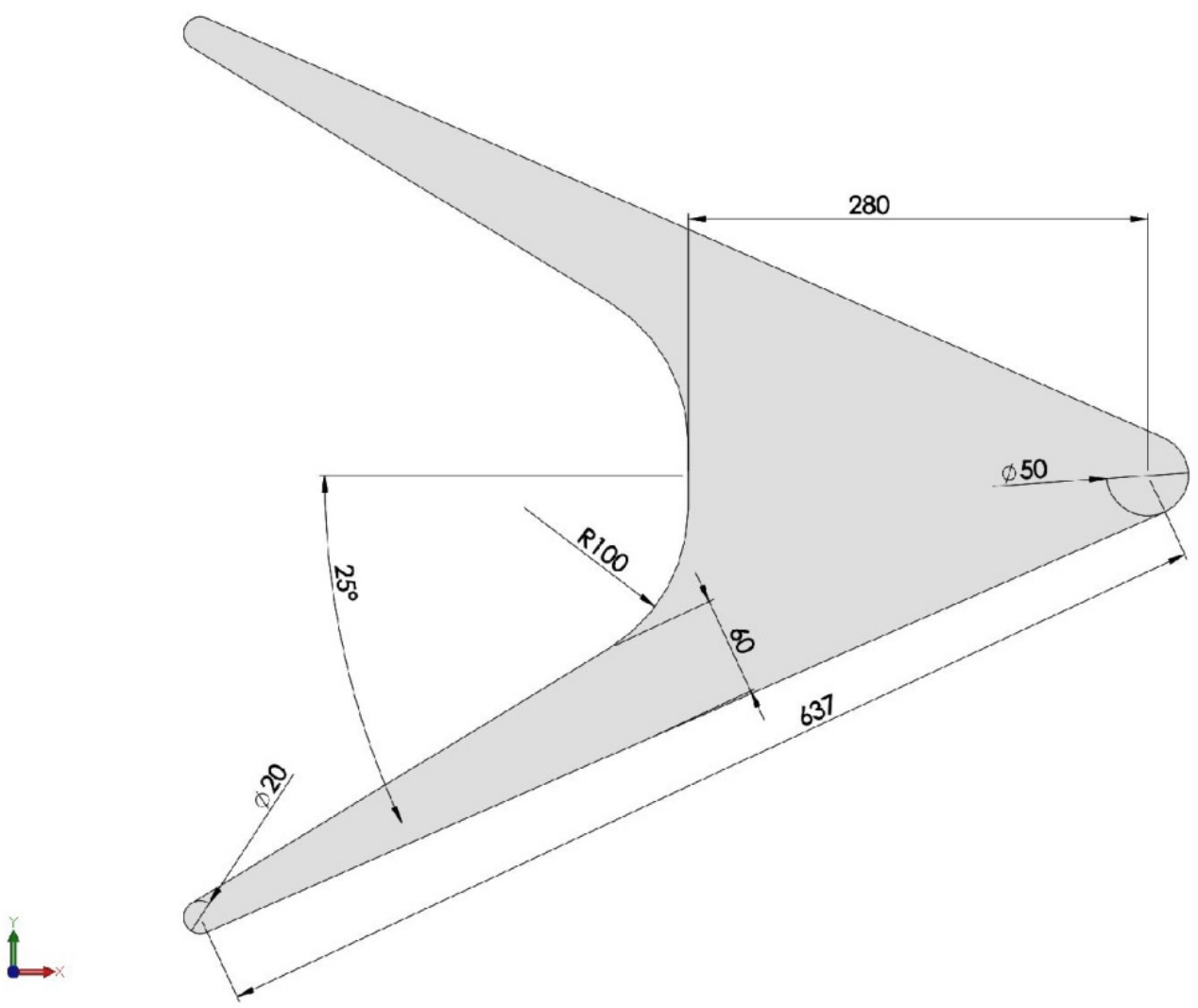

Figure 3. The Delta VLFS configuration modeled for the mooring analysis (top view).

Table 1. The Delta VLFS—additional dimensions.

\begin{tabular}{cc}
\hline Length over all (parallel to the $x$ axis in Figure 3) & $611 \mathrm{~m}$ \\
Breadth over all & $558 \mathrm{~m}$ \\
Depth & $50 \mathrm{~m}$ \\
Draft & $20 \mathrm{~m}$ \\
displacement & $\sim 1,600,000$ ton \\
\hline
\end{tabular}

The ship model was of a generic tanker (or bulk carrier) in weight and dimensions that are typical to the large vessels that we expect to berth at the Delta basin. Table 2 presents the ship's general dimensions and displacement. The natural periods of the Delta in the vertical Degrees of Freedom (DOFs) are presented in Table 3.

Table 2. Ship's specifications.

\begin{tabular}{cc}
\hline Length over all & $230 \mathrm{~m}$ \\
Breadth & $32.5 \mathrm{~m}$ \\
Depth & $19.85 \mathrm{~m}$ \\
Draft & $14 \mathrm{~m}$ \\
Displacement & $84,000 \mathrm{ton}$ \\
\hline
\end{tabular}

Table 3. Natural period of the Delta and the berthed ship.

\begin{tabular}{ccc}
\hline DOF & Delta (s) & Ship (s) \\
\hline Heave & 20.1 & 10.1 \\
Roll & 13.6 & 12.9 \\
Pitch & 13.6 & 9.0 \\
\hline
\end{tabular}


The Delta, anchored at $50 \mathrm{~m}$ water depth, was moored to the seabed by a SPM system, consisting of 24 catenary lines of 3 segments each, as shown in Figure 4 . Table 4 specifies the mooring lines characteristics. For elaborations on this mooring system, see [10].
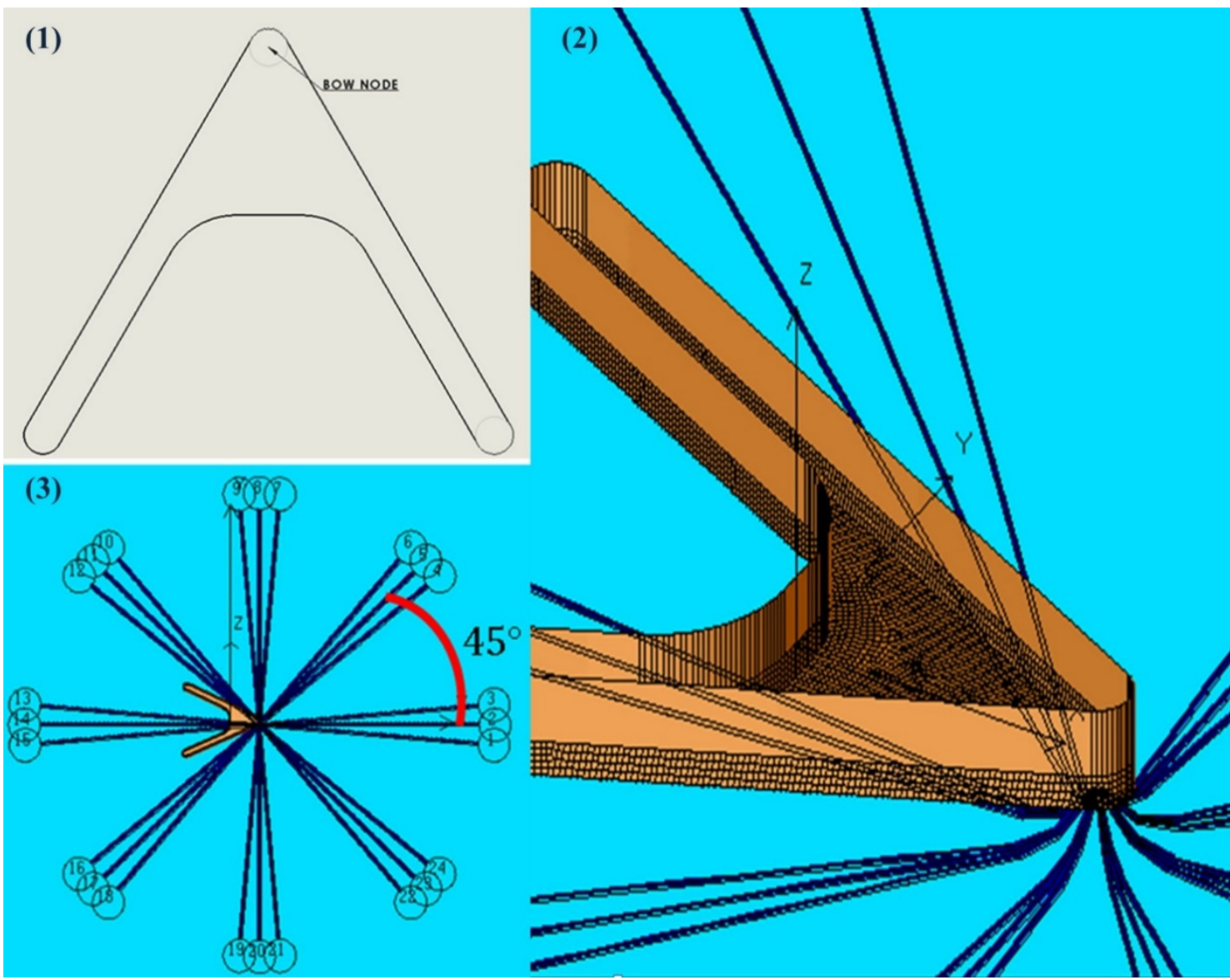

Figure 4. Mooring configuration setup. (1) Bow node location, upper view; (2) connection point; (3) mooring lines arrangement. Note: actual geometric configuration and dimensions of the Delta are as shown in Figure 3.

Table 4. Specification of the Delta's SPM mooring lines.

\begin{tabular}{ccccc}
\hline & & $\begin{array}{c}\text { Segment 1 (Ground): } \\
\text { Chain K4 Studless }\end{array}$ & $\begin{array}{c}\text { Segment 2: } \\
\text { Polyester Cable }\end{array}$ & $\begin{array}{c}\text { Segment 3 (Top): Chain } \\
\text { K4 Studless }\end{array}$ \\
\hline Length & $\mathrm{m}$ & 50 & 1584 & 250 \\
Diameter & $\mathrm{mm}$ & 122 & 223 & 122 \\
Mass & $\mathrm{kg} / \mathrm{m}$ & 326.0 & 31.8 & 326.0 \\
Weight in water & $\mathrm{N} / \mathrm{m}$ & 2429.1 & 78.5 & 2429.1 \\
Stiffness AE & $\mathrm{kN}$ & $1,327,000$ & 384,600 & $1,327,000$ \\
Mean braking load & $\mathrm{kN}$ & 14,360 & 13,730 & 14,360 \\
(MBL) & & & & \\
\hline
\end{tabular}

Following the Permanent International Association of Navigation Congresses (PIANC) [39] and OCIMF [38] recommendations, the berth mooring system consisted of 4 linear mooring lines and 9 fenders. Figure 2 presents the layout of the lines and fenders of the berth. For the study of the system, we considered a relatively stiff and a more compliant setup. For convenience, load cases in which the compliant system was used are marked with " $c$ ", and load cases where the stiff system was used are marked with " $s$ ". 
For both setups, we considered a Super Cone Fenders, SCF2500 (Trelleborg Marine System Company, Trelleborg, Sweden) [40]. Figures 5 and 6 present the stiffness curves and the polynomial representation of the complaint and stiff fenders, respectively.

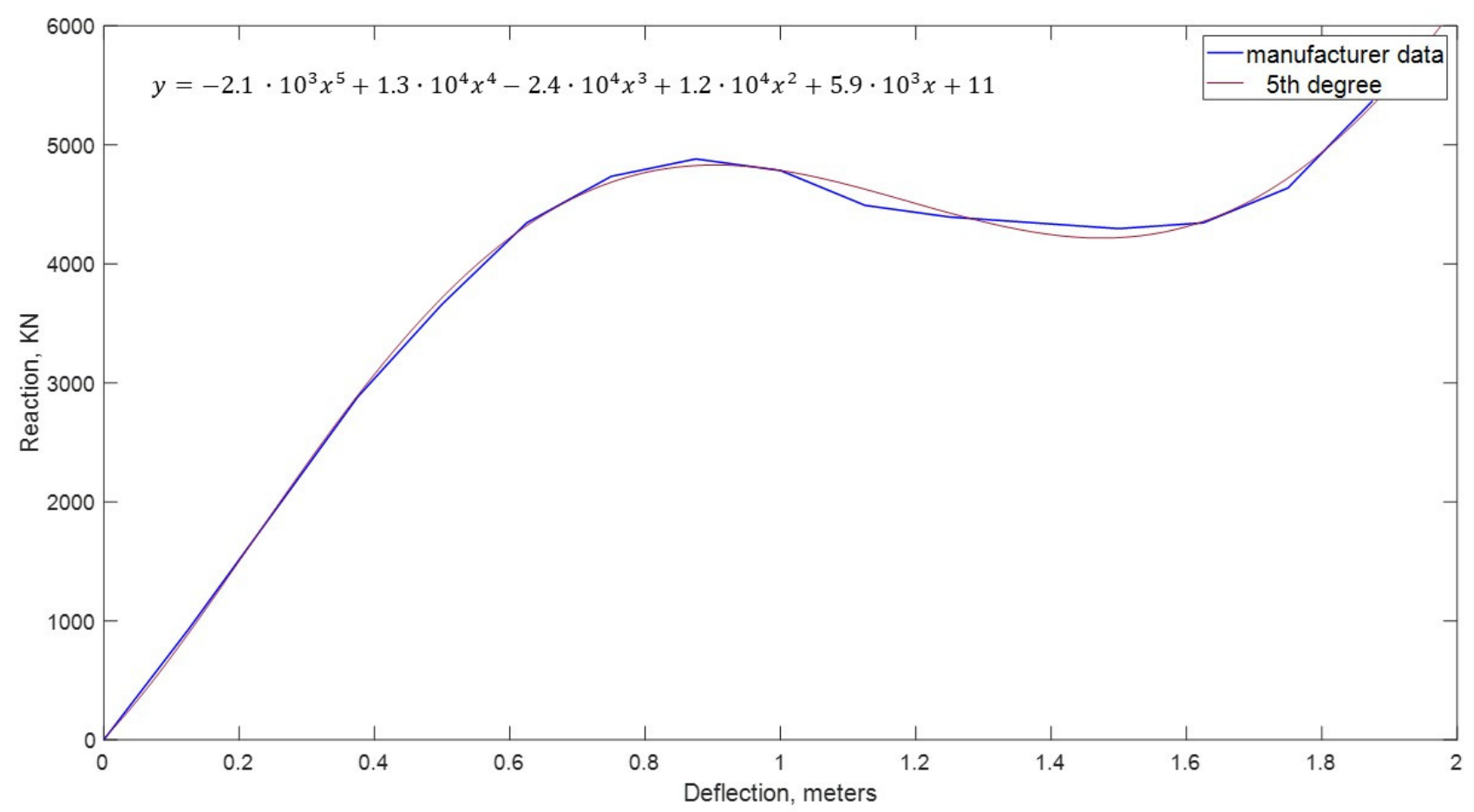

Figure 5. Stiffness curve of the SCN2500 F2.2 fender. The 5th degree polynomial was approximated via MATLAB.

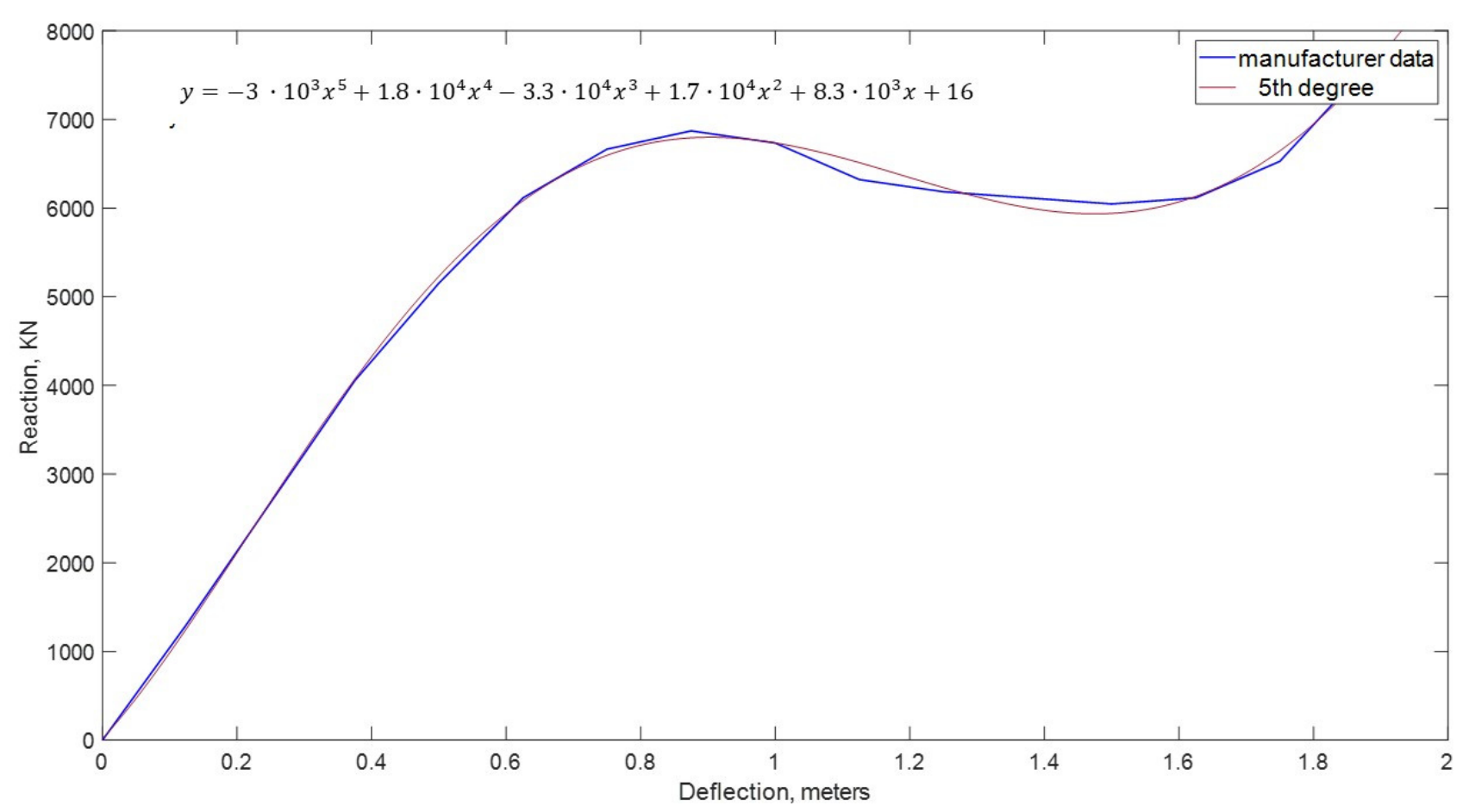

Figure 6. Stiffness curve of the SCN2500 F3.1 fender. The 5th degree polynomial was approximated via MATLAB.

The fenders specifications were: 
1. SCN2500 F2.2

- $\quad$ Length: $2500 \mathrm{~mm}$;

- $100 \%$ energy: $6888.6 \mathrm{kN} / \mathrm{m}$ (72\% deflection);

- $100 \%$ reaction force: $4882 \mathrm{kN}$ (35\% and $72 \%$ deflection);

- Stiffness: see Figure 5 for stiffness curve and its polynomial representation.

2. SCN2500 F3.1:

- Length: $2500 \mathrm{~mm}$;

- $100 \%$ Energy: $9151 \mathrm{kN} / \mathrm{m}$ (72\% deflection);

- $100 \%$ reaction force: $6871 \mathrm{kN}$ (35\% and $72 \%$ deflection);

- Stiffness: see Figure 6 for stiffness curve and its polynomial representation.

The mooring lines were modeled as four single linear lines of the following specifications:

1. Compliant system:

- Length: $\sim 40 \mathrm{~m}$;

- Stiffness: $7420 \mathrm{kN} / \mathrm{m}$;

2. Stiff system:

- $\quad$ Length: $\sim 40 \mathrm{~m}$;

- Stiffness: $10,440 \mathrm{kN} / \mathrm{m}$.

For the evaluation of the results, we considered an $80 \mathrm{~mm}$ polyester rope with no tail (Superline Polyester by the English Braids company [41]). The specifications of the rope are:

- Diameter: $80 \mathrm{~mm}$;

- $\quad$ Stiffness: $931 \mathrm{kN} / \mathrm{m}$;

- MBL: $4473 \mathrm{kN}$.

While the same type of rope was used for both systems, we considered for each line 7 ropes in parallel for the compliant (" $\mathrm{c}$ ") system and 10 ropes in parallel for the stiff (" $\mathrm{s}$ ") system.

For the analysis, we applied sea conditions typical to severe weather from the East Mediterranean Sea. Such wave conditions are at the upper 6th percentile of annual events expected in the region. The real sea conditions were represented by the Joint North Sea Wave Project (JONSWAP) spectrum.

The significant wave heights and peak periods were:

- $\mathrm{H}_{\mathrm{mo}}=2 \mathrm{~m}\left(\mathrm{~T}_{\mathrm{p}}=7.71 \mathrm{~s}\right)$, exceeding probability: $6 \%$

- $\left.\mathrm{H}_{\mathrm{mo}}=2.5 \mathrm{~m}\left(\mathrm{~T}_{\mathrm{p}}=8.62 \mathrm{~s}\right)\right)$, exceeding probability: $3 \%$

- $\mathrm{H}_{\mathrm{mo}}=3 \mathrm{~m}\left(\mathrm{~T}_{\mathrm{p}}=9.44 \mathrm{~s}\right)$, exceeding probability: $2 \%$

- $\mathrm{H}_{\mathrm{mo}}=3.5 \mathrm{~m}\left(\mathrm{~T}_{\mathrm{p}}=10.20 \mathrm{~s}\right)$, exceeding probability: $0.5 \%$

The probabilities were based on long-term wave statistics [42].

\subsubsection{Evaluation of Operability Criteria}

The acceptable motions of the moored ship were in accordance with the PIANC [43] recommendations, presented in Table 5 .

The loads applied to the mooring system were evaluated in terms of permissible loads (i.e., tension in cables and compression in fenders).

As recommended by OCIMF [28], the maximal tension in any single mooring line should not exceed the following level of the maximal breaking load (MBL):

- $55 \%$ MBL for wires;

- $50 \%$ MBL for synthetic ropes;

- $45 \%$ MBL for polyamide.

Unlike the case of the mooring lines, the fender's manufacturer does not specify the maximal permissible load or deflection values. However, for a qualitative analysis such as this, reasonable values may be deduced from the provided data. For the SCN fenders, the installation requirement is to provide clearance for deflection of $75 \%$ of the nominal length. The manufacturer also specifies that $100 \%$ of the impact energy (nominal) is absorbed at about $72 \%$ deflection. 
Table 5. Acceptable motion for moored ships [43].

\begin{tabular}{|c|c|c|c|c|c|c|c|}
\hline Ship Type & Cargo Handling Equipment & Surge (m) & Sway (m) & Heave (m) & Yaw $\left({ }^{\circ}\right)$ & Pitch $\left(^{\circ}\right)$ & Roll $\left({ }^{\circ}\right)$ \\
\hline \multirow{2}{*}{ Container vessels } & $100 \%$ efficiency & 1.0 & 0.6 & 0.8 & 1 & 1 & 3 \\
\hline & $50 \%$ efficiency & 2 & 1.2 & 1.2 & 1.5 & 2 & 6 \\
\hline \multirow{3}{*}{ Bulk carriers } & Cranes & 2.0 & 1.0 & 1.0 & 2 & 2 & 6 \\
\hline & Elevator/bucket-wheel & 1.0 & 0.5 & 1.0 & 2 & 2 & 2 \\
\hline & Conveyor belt & 5.0 & 2.5 & & 3 & & \\
\hline Oil tankers & Loading arms & 3.0 & 3.0 & & & & \\
\hline Gas tankers & Loading arms & 2.0 & 2.0 & & 2 & 2 & 2 \\
\hline
\end{tabular}

\subsubsection{Load Cases}

Table 6 presents the load cases where the ' $\mathrm{c}$ ' indicates the compliant mooring system and ' $\mathrm{s}$ ' indicates the stiff mooring system.

Table 6. Load cases specifications.

\begin{tabular}{cccc}
\hline \multicolumn{2}{c}{ Compliant System $(\mathbf{c})$} & \multicolumn{2}{c}{ Stiff System $(\mathbf{s})$} \\
Load Case & $\mathbf{H}_{\mathbf{m o}}(\mathbf{m})$ & Load Case & $\mathbf{H}_{\mathbf{m o}}(\mathbf{m})$ \\
\hline $\mathrm{c} 1$ & 2 & $\mathrm{~s} 1$ & 2 \\
$\mathrm{c} 2$ & 2.5 & $\mathrm{~s} 2$ & 2.5 \\
$\mathrm{c} 3$ & 3 & $\mathrm{~s} 3$ & 3 \\
$\mathrm{c} 4$ & 3.5 & $\mathrm{~s} 4$ & 3.5 \\
\hline
\end{tabular}

\section{Results}

Typical to all load cases, the Delta's position in load case c2, under the incoming waves is presented in Figure 7. As expected, in all load cases, the structure oscillates within an acute angle to the incoming waves. Due to the asymmetry of the system, caused by the ship berthed to one side of the Delta, the point of equilibrium of the motion is not along the symmetry axis of the Delta.

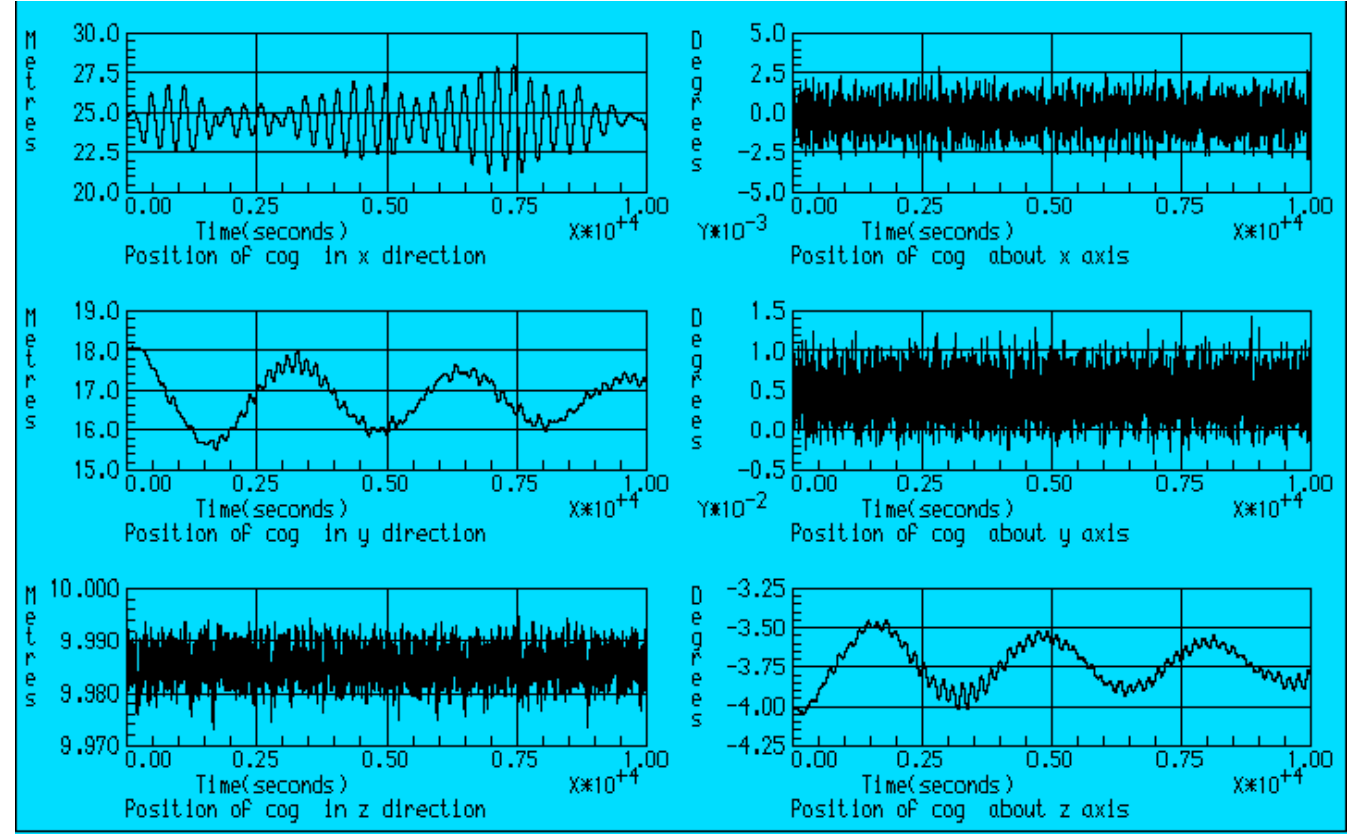

Figure 7. The position of the Delta under the incoming waves-load case c2. Note that the position of the Delta in the horizontal degrees of freedom is dominated by the slow-varying and constant drift load. It is characterized by slow oscillations of large amplitude about a point of equilibrium accompanied by the low amplitude, fast wave frequency oscillation. 
The wave frequency position of the berthed ship along the 10,000-s simulations of the c2 and s2 load cases, are presented in Figures 8 and 9, respectively. The surge and sway motion are relative to the motions of the delta and the heave and rotational motions are absolute. However, in such conditions, the heave and rotational motions of the Delta are minimal and, therefore, negligible. The frequency position of the ship in all load cases are presented in Appendix A.
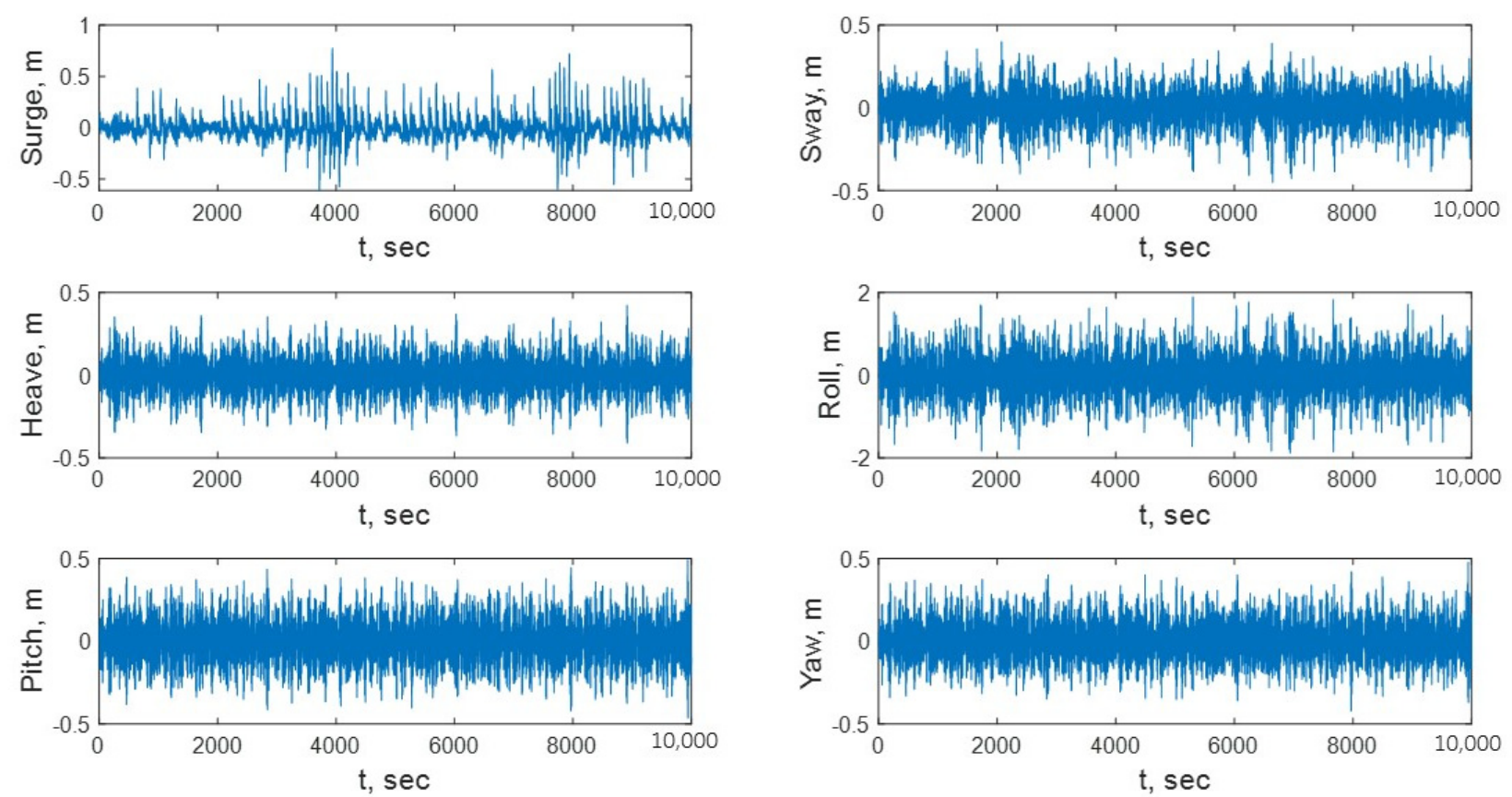

Figure 8. Load case $\mathrm{c} 2 \mathrm{H}_{\mathrm{mo}}=2.5 \mathrm{~m}$-wave frequency position. The surge and sway position are relative to the position of the Delta, the rest are absolute position of the ship.
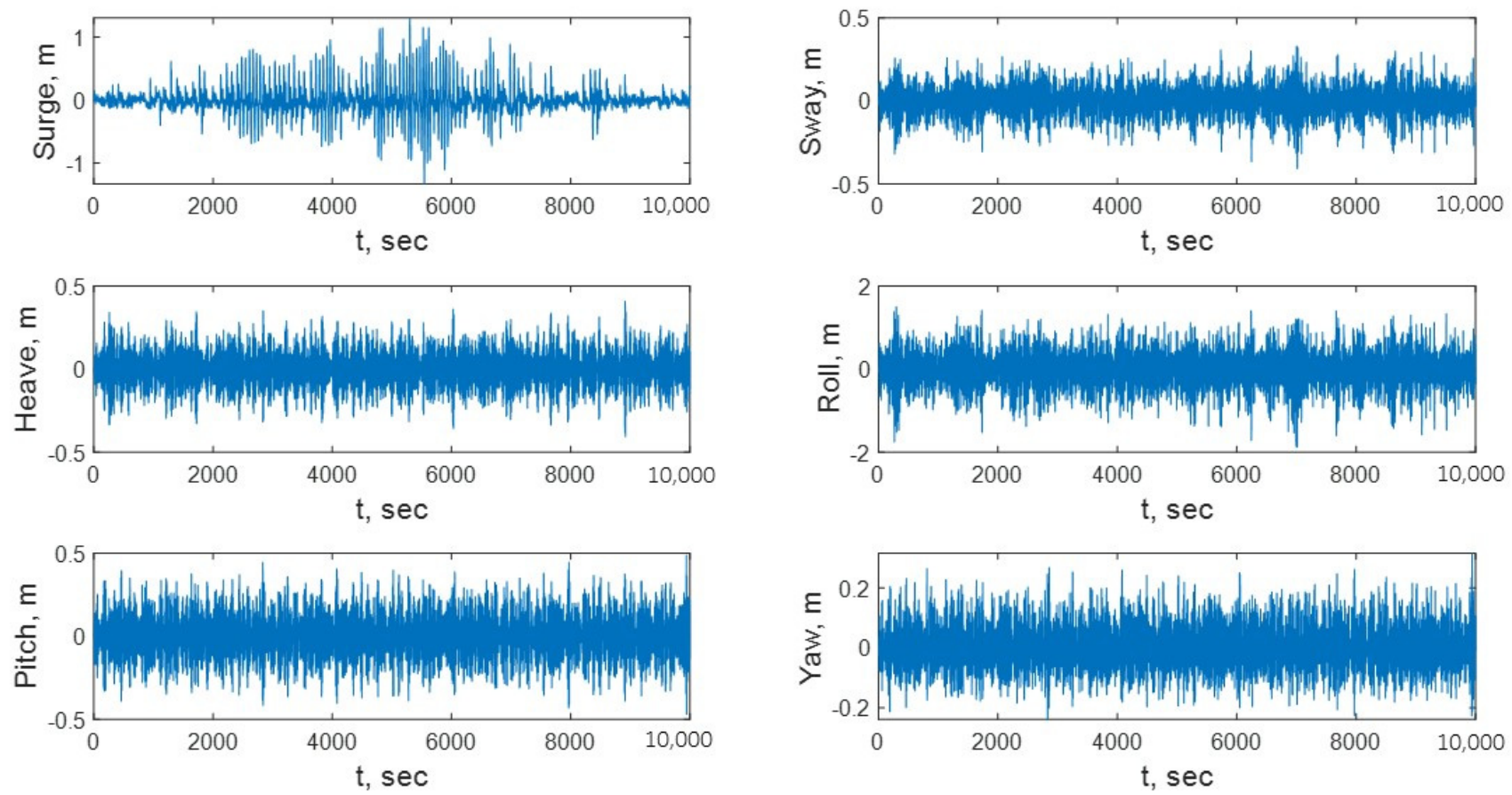

Figure 9. Load case $\mathrm{s} 2 \mathrm{H}_{\mathrm{mo}}=2.5 \mathrm{~m}$-wave frequency position. The surge and sway position are relative to the position of the Delta, the rest are absolute position of the ship. 
Table 7 presents the maximal motions (for a relatively high sea state duration of 10,000 s) of the moored ship in each load case. Table 8 presents the maximal tension in the mooring lines and the maximal compression in the fenders for each load case.

Table 7. Maximal motions in each degree of freedom per load case.

\begin{tabular}{|c|c|c|c|c|c|c|}
\hline Load Case $\left(\mathrm{H}_{\mathrm{mo}}\right)$ & Surge (m) & Sway (m) & Heave (m) & Yaw $\left({ }^{\circ}\right)$ & Pitch $\left(^{\circ}\right)$ & $\operatorname{Roll}\left({ }^{\circ}\right)$ \\
\hline c1 (2) & 0.58 & 0.47 & 0.38 & 0.38 & 0.43 & 2.45 \\
\hline c2 (2.5) & 1.04 & 0.84 & 0.83 & 0.85 & 0.95 & 3.68 \\
\hline c3 (3) & 2.94 & 1.18 & 1.25 & 1.78 & 1.73 & 6.60 \\
\hline c4 (3.5) & 14.31 & 1.26 & 1.70 & 3.43 & 2.39 & 7.63 \\
\hline $\mathrm{s} 1(2)$ & 0.79 & 0.35 & 0.38 & 0.33 & 0.42 & 2.07 \\
\hline $\mathrm{s} 2(2.5)$ & 2.49 & 0.73 & 0.82 & 0.54 & 0.96 & 3.14 \\
\hline s3 (3) & 4.187 & 0.71 & 1.25 & 0.87 & 1.74 & 4.07 \\
\hline s4 (3.5) & 11.35 & 1.02 & 1.67 & 1.55 & 2.49 & 5.63 \\
\hline
\end{tabular}

Table 8. Maximal load on the mooring lines and fenders per load case.

\begin{tabular}{|c|c|c|c|c|c|c|c|c|}
\hline $\begin{array}{c}\text { Load Case } \\
\left(\mathrm{H}_{\mathrm{mo}}\right)\end{array}$ & $\begin{array}{c}\text { Acceptable } \\
\text { Tension on } \\
\text { Lines (\% of } \\
\text { MBL) }\end{array}$ & $\begin{array}{c}\text { Max. } \\
\text { Tension on } \\
\text { Breast Line } \\
(\mathrm{kN})\end{array}$ & $\begin{array}{l}\% \text { of } \\
\text { MBL }\end{array}$ & $\begin{array}{c}\text { Max. } \\
\text { Tension on } \\
\text { Spring Line } \\
(\mathbf{k N})\end{array}$ & $\begin{array}{l}\% \text { of } \\
\text { MBL }\end{array}$ & $\begin{array}{c}\text { Acceptable } \\
\text { Load on } \\
\text { Fenders (kN) }\end{array}$ & $\begin{array}{c}\text { Max. } \\
\text { Compression } \\
\text { on Fender } \\
(\mathbf{k N})\end{array}$ & $\begin{array}{c}\% \text { of Max. } \\
\text { Reaction } \\
\text { Force }\end{array}$ \\
\hline c1 (2) & 50 & 4930 & 16 & 2301 & 7 & 4882 & 2733 & 56 \\
\hline c2 (2.5) & 50 & 8859 & 28 & 2726 & 9 & 4882 & 4630 & 95 \\
\hline c3 (3) & 50 & 18,455 & 59 & 5542 & 18 & 4882 & 4824 & 99 \\
\hline c4 (3.5) & 50 & 29,772 & 95 & 12,515 & 40 & 4882 & 9789 & 200 \\
\hline s1 (2) & 50 & 5297 & 12 & 3704 & 8 & 6871 & 2984 & 43 \\
\hline s2 (2.5) & 50 & 7969 & 18 & 4737 & 11 & 6871 & 5205 & 76 \\
\hline s3 (3) & 50 & 12,442 & 28 & 6348 & 14 & 6871 & 6910 & 101 \\
\hline s4 (3.5) & 50 & 19,041 & 43 & 11,992 & 27 & 6871 & 7515 & 109 \\
\hline
\end{tabular}

The acceptable load cases, in terms of motions, for each ship type and cargo handling equipment were:

1. Container vessel

- $100 \%$ efficiency: $\mathrm{c} 1, \mathrm{~s} 1$;

- $50 \%$ efficiency: c1, c2, s1;

2. Bulk carriers

- Cranes: c1, c2, s1;

- Elevator/bucket-wheel: -;

- Conveyor belt: c1-c3, s1-s3;

3. Oil tanker

- $\quad$ Loading arms: c1-c3, s1, s2;

4. Gas tankers

- Loading arms: -.

The tension loads applied on the berths' mooring lines in load case c2 are presented in Figure 10. While the maximal load varies, the general trend is similar in all load cases. The highest load is applied on the breast lines, from which the stern line is the most loaded (line 27 in Figure 10). From the spring lines, the highest load is applied on the line closer to the stern (line 26 in Figure 10). 


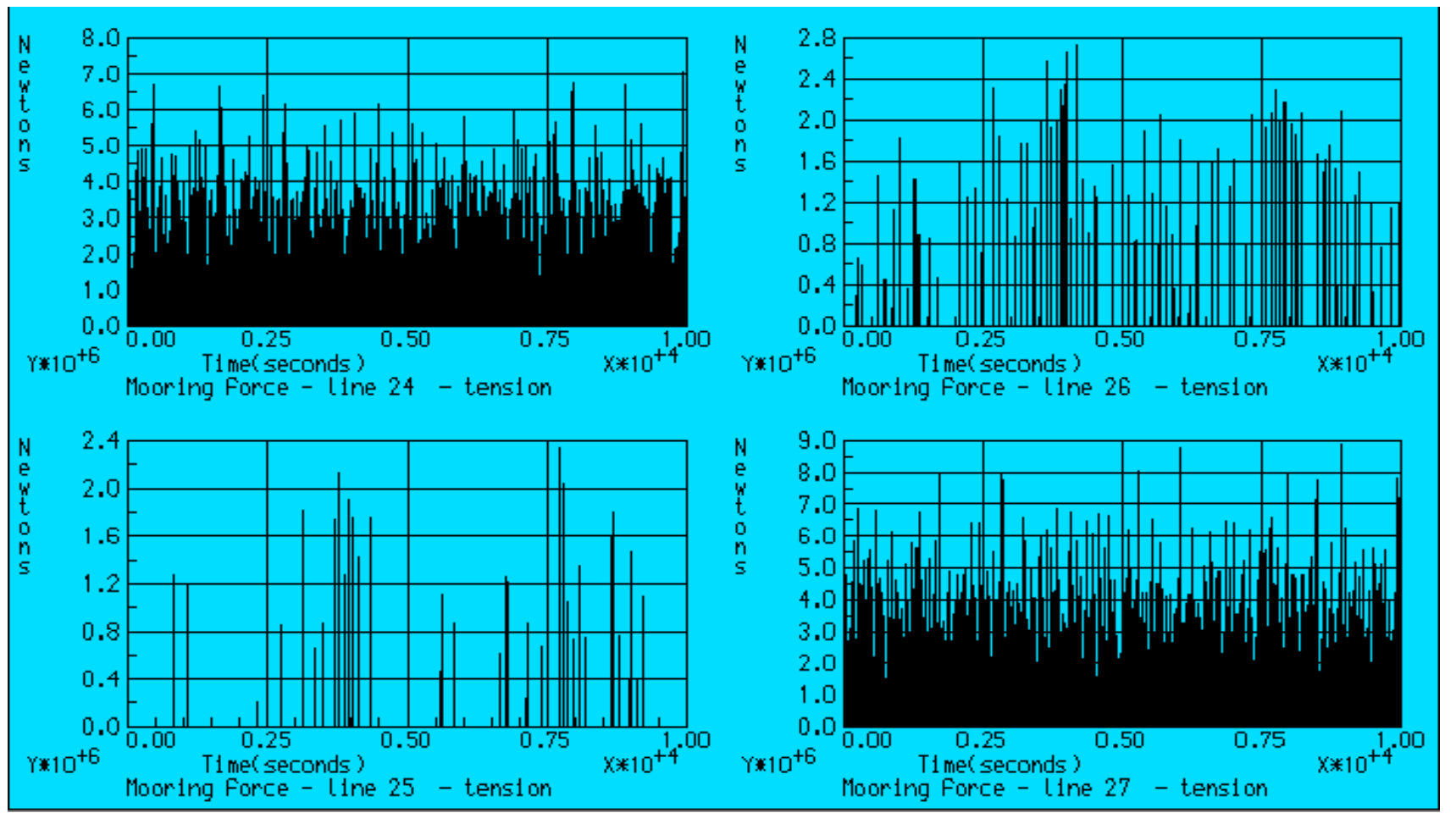

Figure 10. Load case c2-applied tension $(\mathrm{N})$ on the berths' mooring lines.

In terms of fender loading (compression), for significant wave heights of up to $2.5 \mathrm{~m}$ (load cases c1, c2 and s1, s2), the maximal reaction force does not reach the maximal nominal values of the fenders and, therefore, the maximal deflection is less than $35 \%$.

For the assessment of the mooring line tension, we considered for each line 7 ropes for the compliant ("c") system and 10 ropes for the stiff ("s") system. As can be seen in Table 7, the $50 \% \mathrm{MBL}$ is reached for wave heights of over $2.5 \mathrm{~m}$ in the case of the compliant system and, in the case of the stiff system, the maximal tension is within acceptable limits for all load cases.

\section{Discussion and Conclusions}

The wave conditions considered in this study were selected to obtain the operability limits, in order to present the operability of the VLFS that forms a service basin at the selected design site. Indeed, the results are representative of the East Mediterranean Sea, while the method of assessment is general.

As investigated by [44-46] and others, the analysis of the effects of important load mechanisms, such as wave breaking, slamming loads, and two-phase flow, directly influences the design of marine structure. While treating these subjects was out of the scope of this analysis they will be addressed in later stages of the design.

The modeling of the mooring system was simplified into the very basics: compression bearing fenders and tension bearing (linear) ropes. As such, unlike an actual mooring system, the simplified system offered no damping mechanisms (e.g., material damping, friction) that can reduce the risks of resonant effects and suppress loads and motions. For example, while the surge peaks at the $4000 \mathrm{~s}$ and $8000 \mathrm{~s}$ can be explained as a dynamic reaction to the Delta's surge motion, that peaks approximately at those instances as well (see Figure 7), still, the amplitude of the ship's motion may well be affected by a resonance response. However, considering that such phenomena is directly related to the specific ship dimensions, its dimension-to-wavelength ratio [47], and to the mooring system specification, it is an important matter to attend to at later stages of the more detailed design However, as it is, the study indicates that for most types of ships and cargo-handling 
equipment, the sheltered basin provides adequate protection and allow for safe berthing conditions for waves conditions of up to $H_{\mathrm{mo}}=2.5 \mathrm{~m}$ (operability during $95 \%$ of the year). In some cases, higher wave conditions are acceptable as well.

Providing additional assurance to the validity of the analysis, we conducted a sensitivity test in which we forced the incoming wave direction to a different, less acute, angle of about 15 degrees. As can be seen in Figure 11, the applied tension on the mooring lines is even lower than in the more acute angle incoming direction presented in Figure 10. Therefore, we are confident in the validity of our findings.

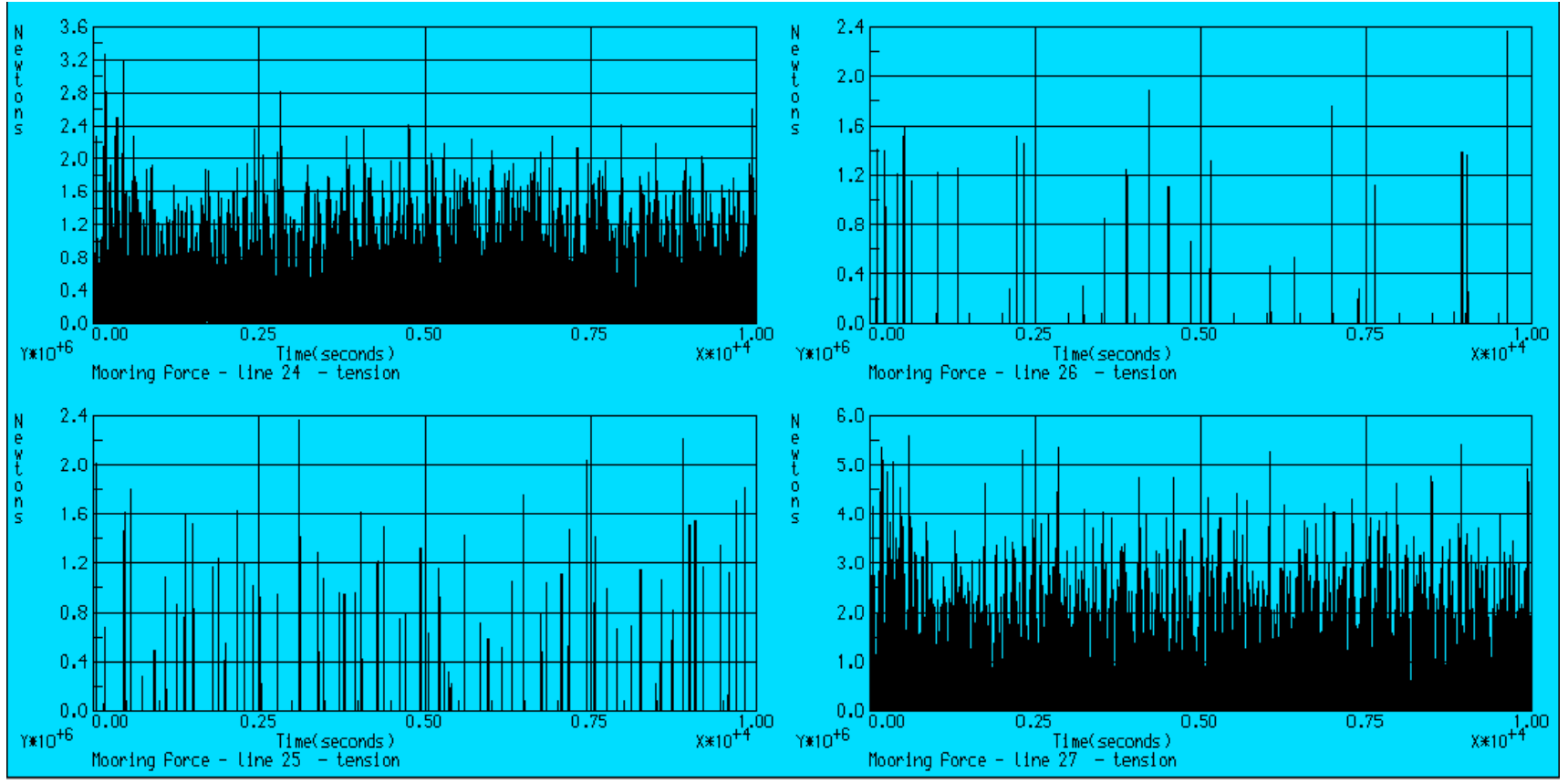

Figure 11. Sensitivity test-applied tension $(\mathrm{N})$ on the berths' mooring lines. Incoming wave angle of about 15 degrees from the head-on direction; otherwise, similar wave condition as for the c2 load case.

We expect that a detailed design and optimization of the mooring system may improve the operability of the sheltered basin. First, such design will include modeling the material damping of the fenders and the friction between the moored ship and the fenders, which will reduce the loads and motions as well as reduce resonant effects. Second, the design will include a more specific selection of the mooring equipment. Adjusting the mooring system specifically to each expected ship type, size, or cargo-handling operation, will improve its performance and assure the expected minimal downtime operability of the sheltered basin. In addition, if required, a structural optimization of the hull, oriented towards maximizing the basin's performance will surely produce significant improvements as well.

The study clearly points towards a general trend in the mooring line tension. The results show that the highest loads are applied on the breast line and the loads applied on the spring lines are lower. However, as all loads are practically in the same order of magnitude, especially in the case of the bow and stern division, we cannot recommend optimization measures regarding the rope selection or division between the mooring lines.

As presented in the appendix figures, the compliant system's surge increases with the wave height. Since the surge DOF of the moored ship is dominated by the second-order drift loads, the nonlinear growth of the surge amplitude with the increase of the wave height is expected. In addition, for wave heights of up to $3 \mathrm{~m}$ the surge motions are much lower with the compliant mooring, while the sway and yaw motions are lower with the stiff mooring. As, typically, the surge is the most critical, we conclude that the compliant mooring is more efficient. 
As expected and practical, the vertical movements (heave, roll, pitch) are not considerably affected by the mooring stiffness.

As a design tool, especially in early, preliminary stages, the application of the timedomain simulation using AQWA-DRIFT is practical and efficient. The evaluated results of the mooring system's loads and the ship's motion provide comparable numerical measures to the basin's operability and may be readily used as an integral part of the design methodology of the Delta concept.

Author Contributions: Conceptualization, R.G. and N.D.; methodology, R.G.; software, R.G.; validation, R.G., N.D.; formal analysis, R.G.; investigation, N.D.; resources, N.D.; writing-original draft preparation, R.G.; writing-review and editing, N.D.; visualization, R.G.; supervision, N.D. All authors have read and agreed to the published version of the manuscript.

Funding: This research received no external funding.

Institutional Review Board Statement: Not applicable.

Informed Consent Statement: Not applicable.

Data Availability Statement: Please refer to corresponding author.

Conflicts of Interest: The authors declare no conflict of interest.

\section{Appendix A}

The wave frequency position of the berthed ship along the 10,000-s simulations of each load case, are presented in Figures A1-A8. Figures A1-A4 are of the compliant (c) mooring system and Figures A5-A8 are of the stiff (s) system. In all, the surge and sway position are relative to the position of the Delta and all other DOF's are the absolute position of the ship.
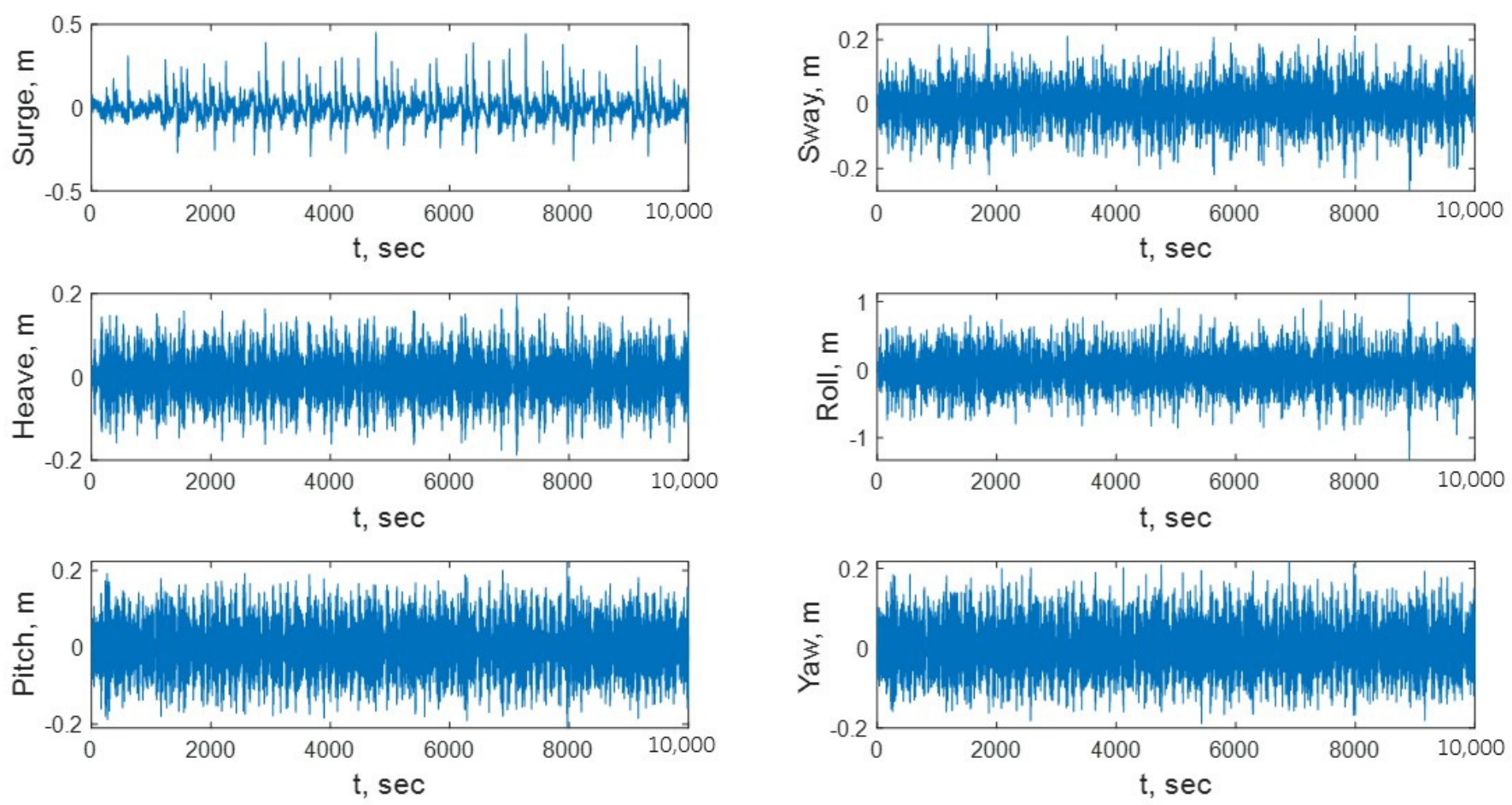

Figure A1. Load case $\mathrm{c} 1\left(\mathrm{H}_{\mathrm{mo}}=2 \mathrm{~m}\right)$-wave frequency position. The surge and sway positions are relative to the position of the Delta, the other positions are absolute position of the ship. 

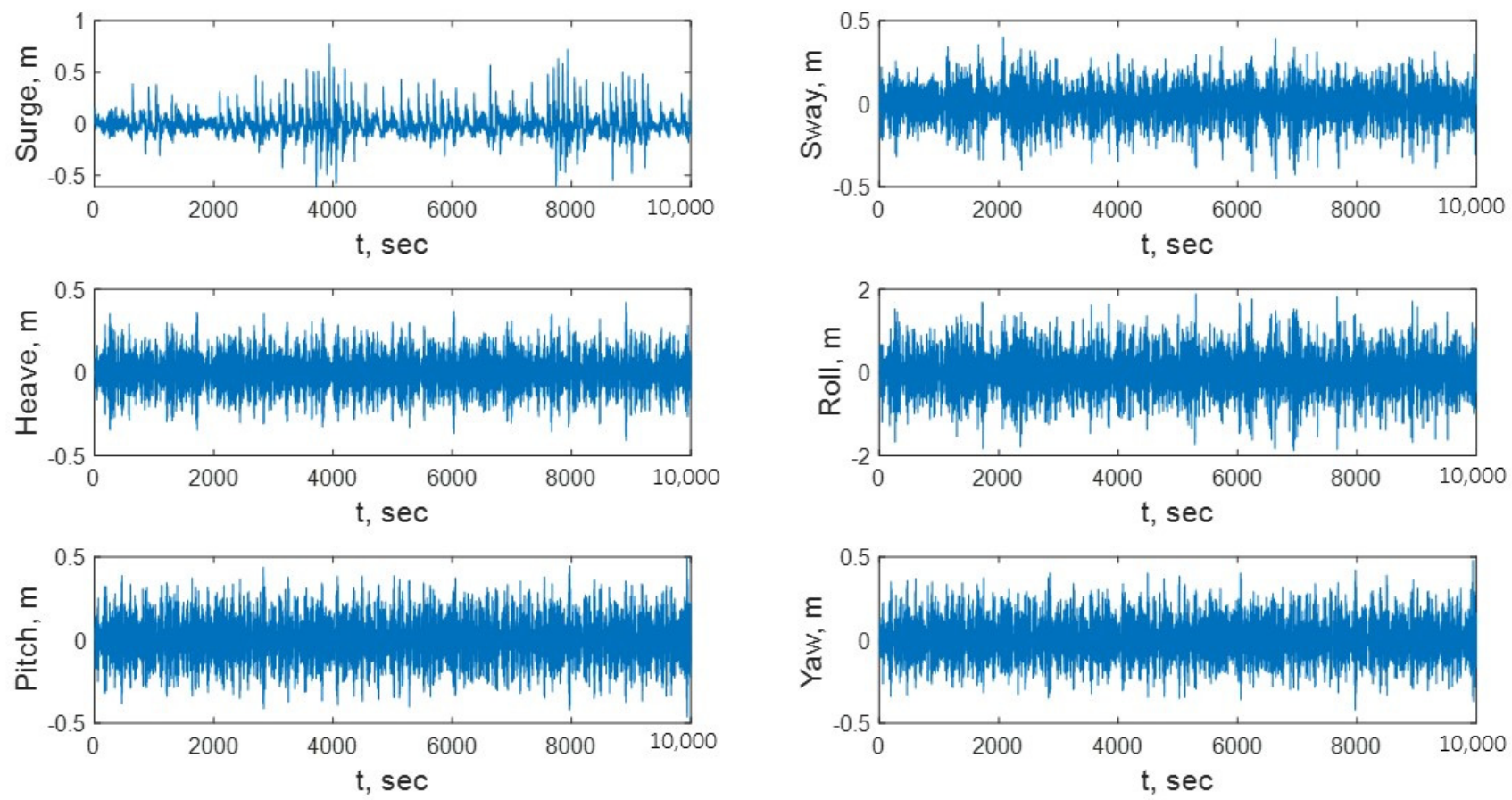

Figure A2. Load case $\mathrm{c} 2\left(\mathrm{H}_{\mathrm{mo}}=2.5 \mathrm{~m}\right)$-wave frequency position. The surge and sway positions are relative to the position of the Delta, the other positions are absolute position of the ship.
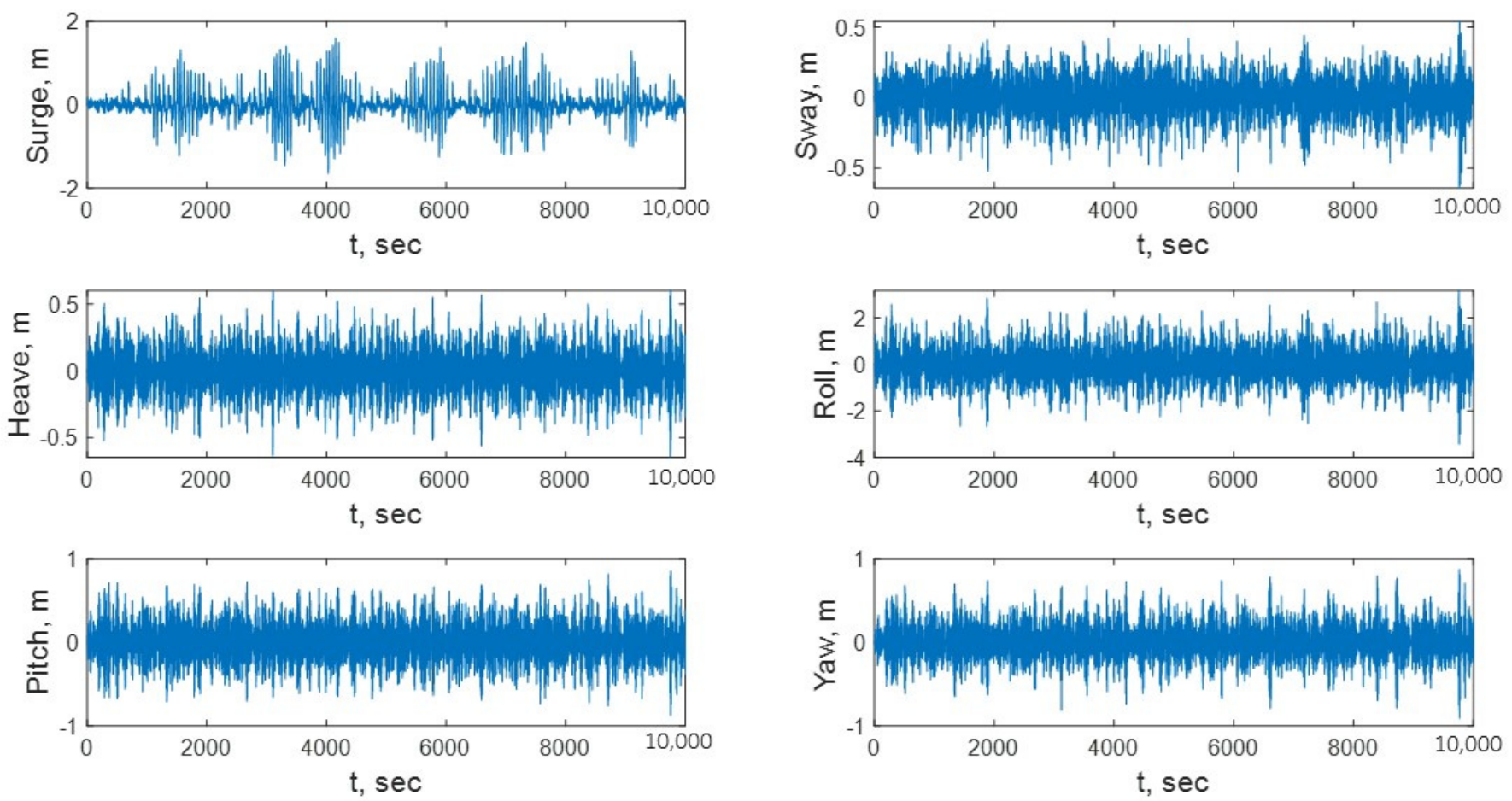

Figure A3. Load case $\mathrm{c} 3\left(\mathrm{H}_{\mathrm{mo}}=3 \mathrm{~m}\right)$-wave frequency position. The surge and sway position are relative to the position of the Delta, the other positions are absolute position of the ship. 

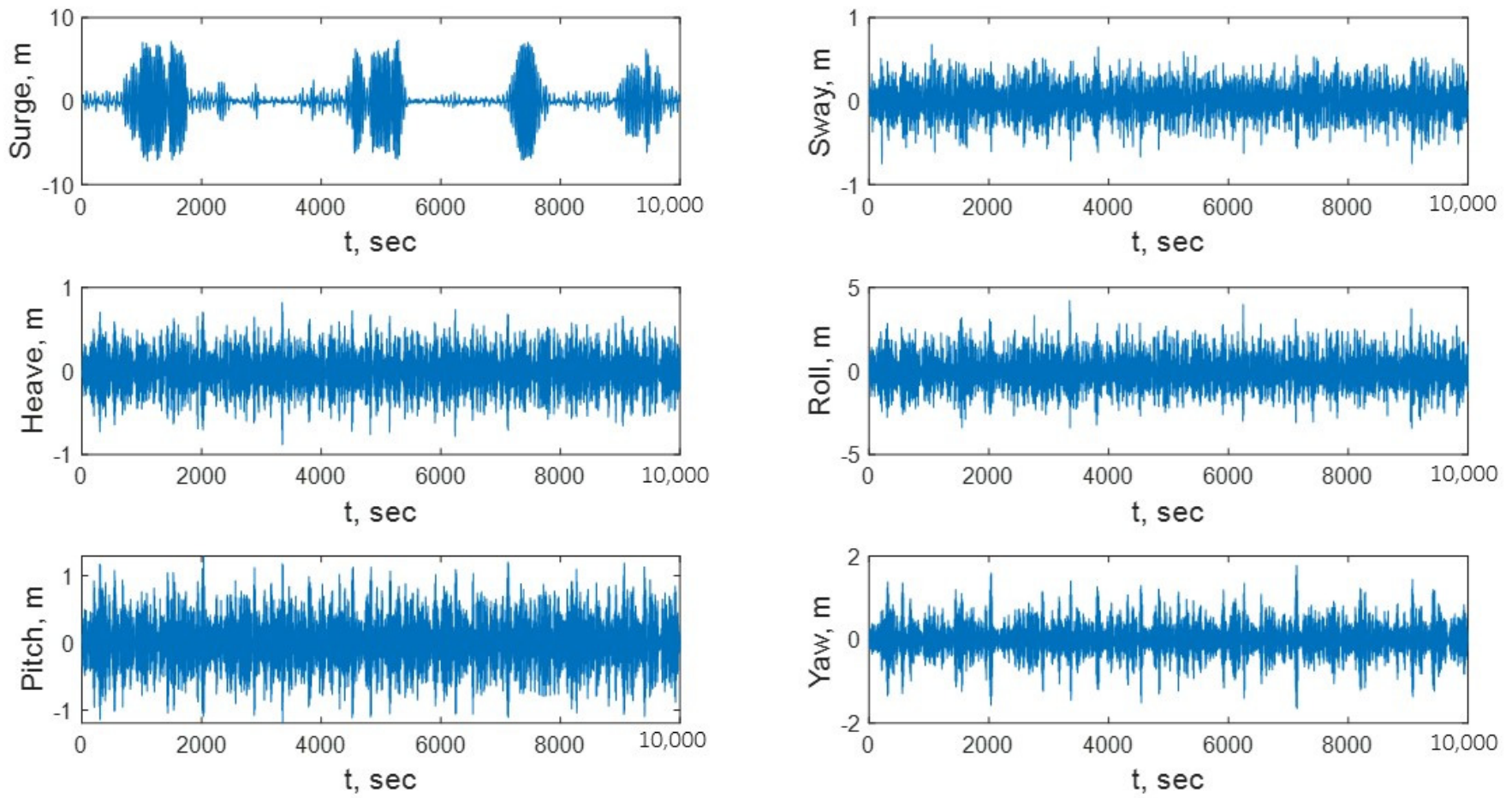

Figure A4. Load case $\mathrm{c} 4\left(\mathrm{H}_{\mathrm{mo}}=3.5 \mathrm{~m}\right)$-wave frequency position. The surge and sway positions are relative to the position of the Delta, the other positions are absolute position of the ship.
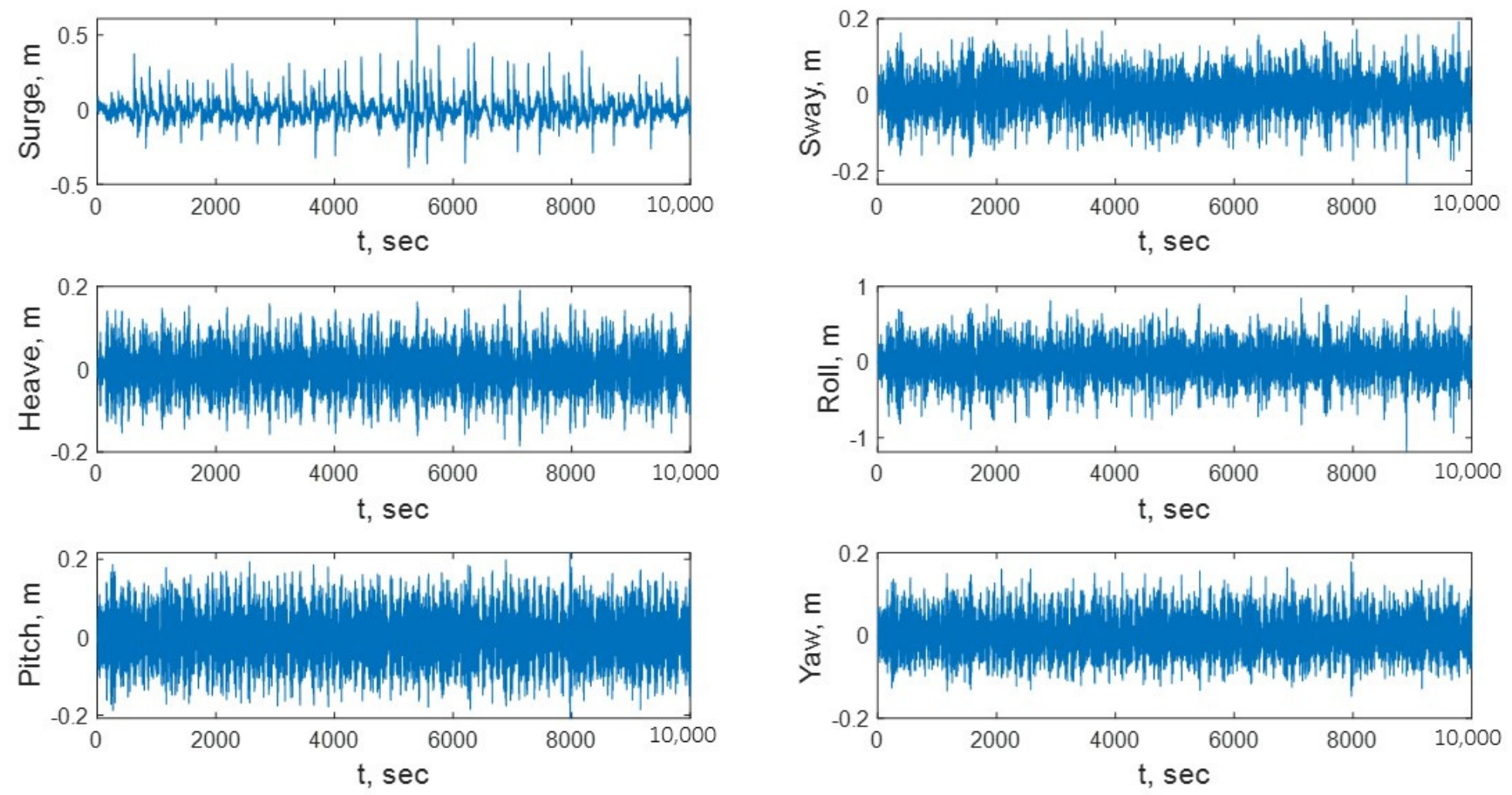

Figure A5. Load case s1 $\left(\mathrm{H}_{\mathrm{mo}}=2 \mathrm{~m}\right)$-wave frequency position. The surge and sway positions are relative to the position of the Delta, the other positions are absolute position of the ship. 

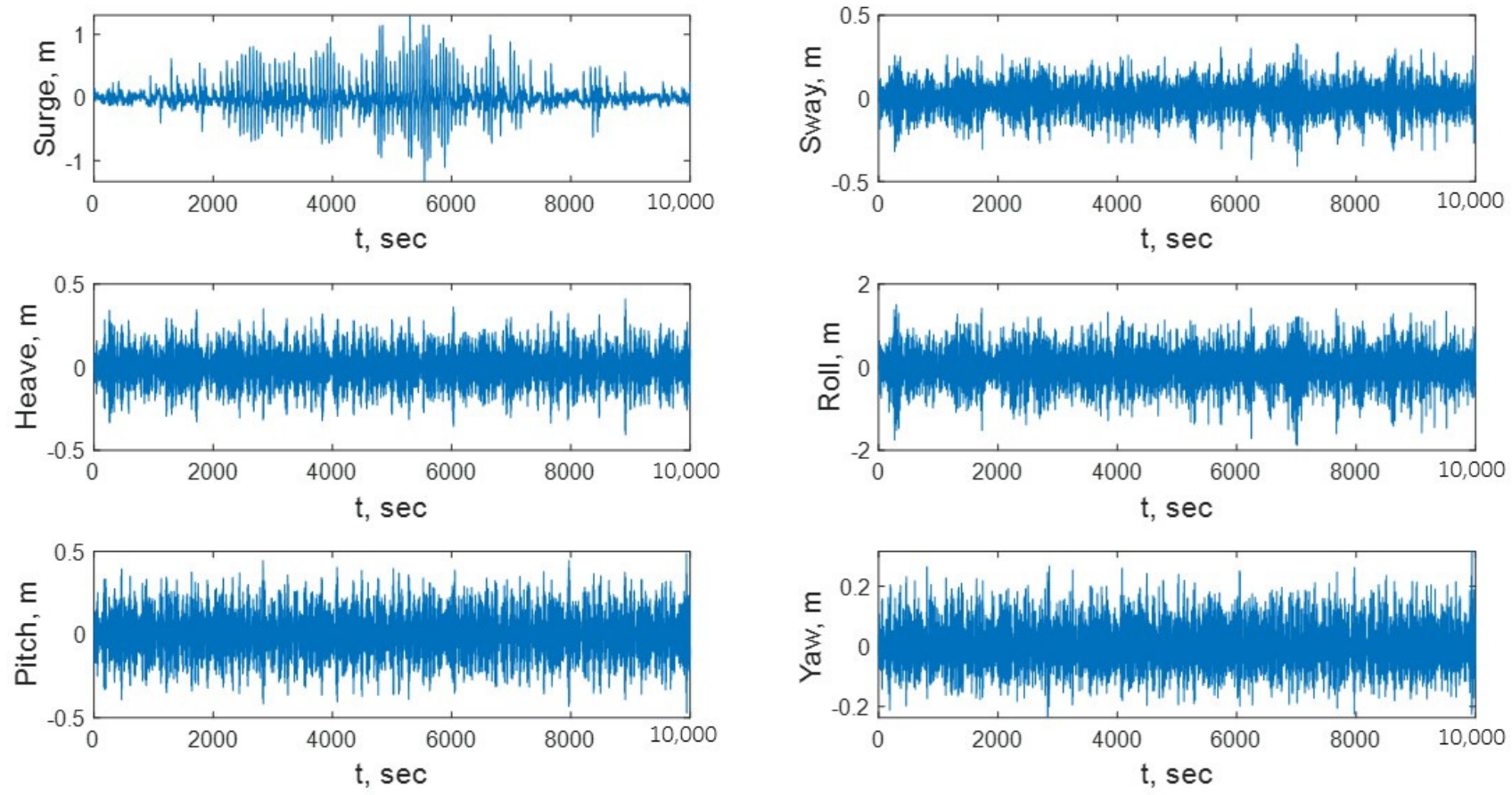

Figure A6. Load case s2 $\left(\mathrm{H}_{\mathrm{mo}}=2.5 \mathrm{~m}\right)$-wave frequency position. The surge and sway positions are relative to the position of the Delta, the other positions are absolute position of the ship.
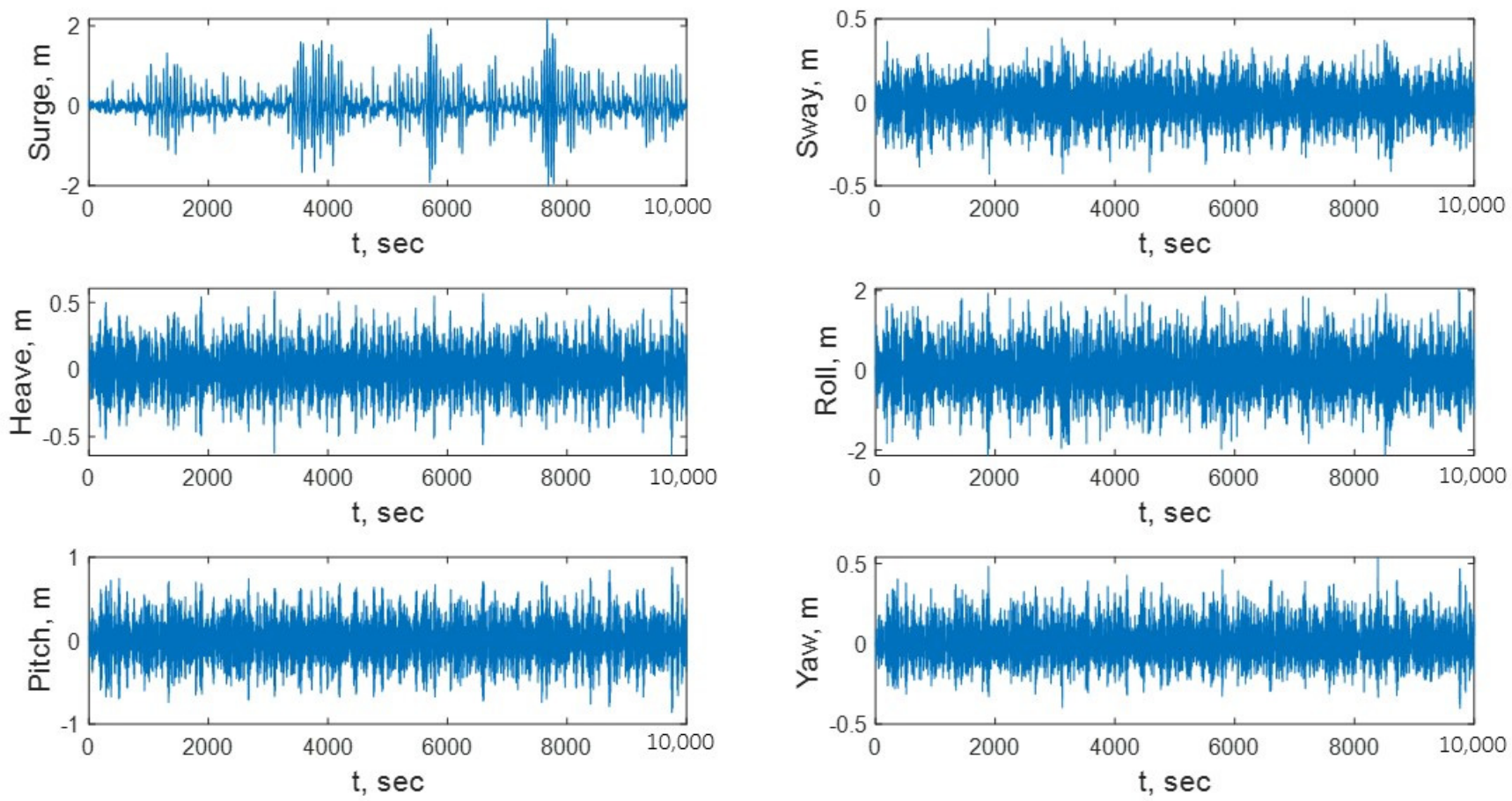

Figure A7. Load case $\mathrm{s} 3\left(\mathrm{H}_{\mathrm{mo}}=3 \mathrm{~m}\right)$-wave frequency position. The surge and sway positions are relative to the position of the Delta, the other positions are absolute position of the ship. 

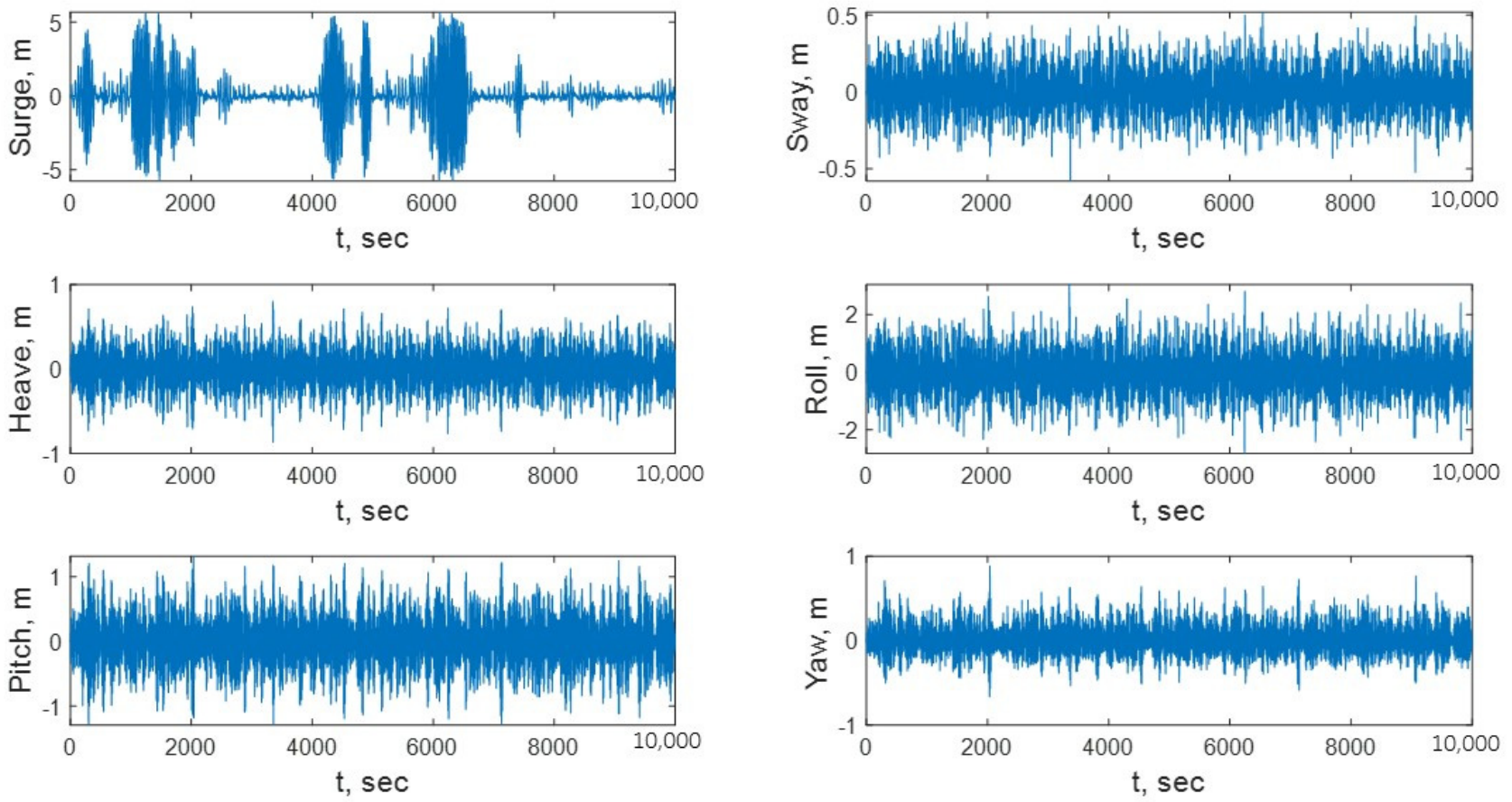

Figure A8. Load case $\mathrm{s} 4\left(\mathrm{H}_{\mathrm{mo}}=3.5 \mathrm{~m}\right)$-wave frequency position. The surge and sway positions are relative to the position of the Delta, the other positions are absolute position of the ship.

\section{References}

1. Wang, G.; Goldfeld, Y.; Drimer, N. Expanding coastal cities-Proof of feasibility for modular floating structures (MFS). J. Clean. Prod. 2019, 222, 520-538. [CrossRef]

2. UNCTAD. Handbook of Statistics 2020-The World Development Status; United Nations Pablications: New York, NY, USA, 2020. Available online: https://unctad.org/system/files/official-document/tdstat45_en.pdf (accessed on 13 September 2021).

3. Ranasinghe, R. On The Need for a New Generation of Coastal Change Models for the 21st Century. Sci. Rep. 2020, 10, 2010. [CrossRef] [PubMed]

4. Wang, C.M.; Wang, B.T. Colonization of the ocean and VLFS technology. In Very Large Floating Structures; Wang, C.M., Watanabe, E., Utsunomiya, T., Eds.; Taylor \& Francis: New York, NY, USA, 2008; pp. 1-20.

5. Wang, C.M.; Tay, Z.Y.; Takagi, K.; Utsunomiya, T. Literature review of methods for mitigating hydroelastic response of VLFS under wave action. Appl. Mech. Rev. 2010, 63, 030802. [CrossRef]

6. Wang, C.M.; Wang, B.T. (Eds.) Great Ideas Float to the top. In Large Floating Structure: Technological Advances; Springer: Singapore, 2015; p. 334.

7. Kim, J.-G.; Cho, S.-P.; Kim, K.-T.; Lee, P.-S. Hydroelastic design contour for the preliminary design of very large floating structures. Ocean. Eng. 2014, 78, 112-123. [CrossRef]

8. Wu, L.; Wang, Y.; Li, Y.; Xiao, Z.; Li, Q. Simplified algorithm for evaluating the hydrodynamic performance of very large modular semi-submersible structures. Ocean. Eng. 2017, 140, 105-124. [CrossRef]

9. Lamas-Pardo, M.; Iglesias, G.; Carral, L. A review of Very Large Floating Structures (VLFS) for coastal and offshore uses. Ocean. Eng. 2015, 109, 677-690. [CrossRef]

10. Drimer, N.; Gafter, R. Delta-type VLFS-hydrodynamic aspects. Ships Offshore Struct. 2018, 13, 352-365. [CrossRef]

11. Gafter, R.; Drimer, N. A Design Method to Assess the Primary Strength of the Delta-Type VLFS. J. Mar. Sci. Eng. 2021, 9, 1026. [CrossRef]

12. Antonini, A.; Archetti, R.; Lamberti, A. Wave simulation for the design of an innovative quay wall: The case of Vlorë Harbour. Nat. Hazards Earth Syst. Sci. 2017, 17, 127-142. [CrossRef]

13. Suzuki, H.; Bhattacharya, B.; Fujikubo, M.; Hudson, D.A.; Riggs, H.R.; Seto, H.; Shin, H.; Shugar, T.A.; Yasuzawa, Y.; Zong, Z. ISSC committee VI.2: Very large floating structures. In Proceedings of the 16th International Ship and Offshore Structures Congress, Southhampton, UK, 20-25 August 2006; pp. 391-442.

14. Wang, C.M.; Tay, Z.Y. Very large floating structures: Applications, research and development. Procedia Eng. 2011, 14, 62-72. [CrossRef]

15. Watanabe, E.; Wang, C.M.; Utsunomiya, T. Very Large Floating Structures: Applications, Analysis and Design; Centre for Offshore Research and Engineering, National University of Singapore: Singapore, 2004.

16. Newman, J.N. Marine Hydrodynamics; MIT Press: Cambridge, UK, 1977. 
17. Tsui, Y.Y.; Huang, Y.C.; Huang, C.L.; Lin, S.W. A finite-volume-based approach for dynamic fluid-structure interaction. Numer. Heat Transf. Part B Fundam. 2013, 64, 326-349. [CrossRef]

18. Xiang, T.; Istrati, D.; Yim, S.C.; Buckle, I.G.; Lomonaco, P. Tsunami loads on a representative coastal bridge deck: Experimental study and validation of design equations. J. Waterw. Port Coast. Ocean Eng. 2020, 146, 04020022. [CrossRef]

19. Westphalen, J.; Greaves, D.M.; Raby, A.; Hu, Z.Z.; Causon, D.M.; Mingham, C.G.; Omidvar, P.; Stansby, P.K.; Rogers, B.D. Investigation of wave-structure interaction using state of the art CFD techniques. Open J. Fluid Dyn. 2014, 4, 18. [CrossRef]

20. Ren, B.; Jin, Z.; Gao, R.; Wang, Y.X.; Xu, Z.L. SPH-DEM modeling of the hydraulic stability of 2D blocks on a slope. J. Waterw. Port Coast. Ocean. Eng. 2014, 140, 04014022. [CrossRef]

21. Hasanpour, A.; Istrati, D.; Buckle, I. Coupled SPH-FEM Modeling of Tsunami-Borne Large Debris Flow and Impact on Coastal Structures. J. Mar. Sci. Eng. 2021, 9, 1068. [CrossRef]

22. Faltinsen, O.M. Hydrodynamics of marine and offshore structures. J. Hydrodyn. 2015, 26, 835-847. [CrossRef]

23. Hirdaris, S.E.; Bai, W.; Dessi, D.; Ergin, A.; Gu, X.; Hermundstad, O.A.; Huijsmans, R.; Iijima, K.; Nielsen, U.D.; Parunov, J.; et al. Loads for use in the design of ships and offshore structures. Ocean. Eng. 2014, 78, 131-174. [CrossRef]

24. Hughes, O.; Paik, J.K. Ship Structural Analysis and Design; Society of Naval Architects and Marine Engineers: Jersey City, NJ, USA, 2010.

25. Sharma, R.; Kim, T.W.; Storch, R.L.; Hopman, H.J.J.; Erikstad, S.O. Challenges in computer applications for ship and floating structure design and analysis. CAD Comput. Aided Des. 2012, 44, 166-185. [CrossRef]

26. Birk, L.; Clauss, G.F. Rational design criteria and their application to hull form optimisation of floating systems in random seas. In Practical Design of Ships and Other Floating Structures: Eighth International Symposium-PRADS 2001; Wu, Y.-S., Zhou, G.-J., Cui, W.-C., Eds.; Elsevier: Amsterdam, The Netherlands, 2001; pp. 275-283.

27. Boccotti, P. Wave Mechanics for Ocean Engineering, 1st ed.; Elsevier B.V.: Amsterdam, The Netherlands, 2000.

28. Dean, R.G.; Dalrymple, R.A. Water Wave Mechanics for Engineers and Scientists; World Scientific Publishing Co. Pte. Ltd.: Singapore, 1991. [CrossRef]

29. Goda, Y. Random Seas and Design of Maritime Structures, 2nd ed.; World Scientific Publishing Co. Pte. Ltd.: Singapore, 2000. [CrossRef]

30. Ding, J.; Wu, Y.; Xie, Z.; Yang, W.; Wang, S.; Yu, J.; Yu, T. Overview: Research on hydroelastic responses of VLFS in complex environments. Mar. Struct. 2021, 78, 102978. [CrossRef]

31. Anagnostopoulos, S.A. Dynamic response of offshore platforms to extreme waves including fluid-structure interaction. Eng. Struct. 1982, 4, 179-185. [CrossRef]

32. Istrati, D.; Buckle, I.G. Effect of fluid-structure interaction on connection forces in bridges due to tsunami loads. In Proceedings of the 30th US-Japan Bridge Engineering Workshop, Washington, DC, USA, 21-23 October 2014; pp. 21-23.

33. Choi, S.J.; Lee, K.H.; Gudmestad, O.T. The effect of dynamic amplification due to a structure's vibration on breaking wave impact. Ocean. Eng. 2015, 96, 8-20. [CrossRef]

34. Rahmdel, S.; Wang, B.; Han, C.; Kim, K.; Park, S. A parametric study of spar-type floating offshore wind turbines (FOWTs) by numerical and experimental investigations. Ships Offshore Struct. 2016, 11, 818-832. [CrossRef]

35. Nallayarasu, S.; Senthil Kumar, N. Experimental and numerical investigation on hydrodynamic response of buoy form spar under regular waves. Ships Offshore Struct. 2017, 12, 19-31. [CrossRef]

36. Gourlay, T.; von Graefe, A.; Shigunov, V.; Lataire, E. Comparison of AQWA, GL Rankine, MOSES, Octapus, PDStrip and WAMIT with model test results for cargo ship wave-induced motions in shallow water. In Proceedings of the ASME 2015 34th International Conference on Ocean, Offshore and Arctic Engineering, St. John's, NL, Canada, 31 May-5 June 2015.

37. Gafter, R. Delta Type VLFS for Open Sea; Technion-Israel Institute of Technology: Haifa, Israel, 2016.

38. OCIMF. Mooring Equipment Guidelines (MEG3); OCIMF: London, UK, 2002.

39. PIANC. Guidelines for the Design of Fenders Systems: 2002; PIANC: Brussels, Belgium, 2002.

40. Trelleborg Marine and Infrastructure. Available online: https://www.trelleborg.com/en/marine-and-infrastructure (accessed on 9 May 2021).

41. English Braids | UK Manufacturer of Ropes and Cords. Available online: https://www.englishbraids.com/ (accessed on 26 July 2021).

42. Levin, A.; Glozman, M.; Keren, Y.; Trifonofa, E. Processing of Hydrographic Data for the Ashdod Region (No. P.N. 892/19); CAMERICoastal and Marin Engineering Research Institute, Technion City: Haifa, Israel, 2019.

43. PIANC. Criteria for Movements of Moored Ships in Harbours: A Practical Guide (Supplement to Bulletin No 88); PIANC: Brussels, Belgium, 1995.

44. Peregrine, D.H.; Bredmose, H.; Bullock, G.; Obrhai, C.; Müller, G.; Wolters, G. Water wave impact on walls and the role of air. In Coastal Engineering 2004; World Scientific: Singapore, 2005; Volume 4, pp. 4005-4017.

45. Leschka, S.; Oumeraci, H. Solitary waves and bores passing three cylinders-effect of distance and arrangement. Coast. Eng. Proc. 2014, 1, 39. [CrossRef]

46. Istrati, D.; Buckle, I.; Lomonaco, P.; Yim, S. Deciphering the tsunami wave impact and associated connection forces in open-girder coastal bridges. J. Mar. Sci. Eng. 2018, 6, 148. [CrossRef]

47. Xiang, T.; Istrati, D. Assessment of Extreme Wave Impact on Coastal Decks with Different Geometries via the Arbitrary Lagrangian-Eulerian Method. J. Mar. Sci. Eng. 2021, 9, 1342. [CrossRef] 